bioRxiv preprint doi: https://doi.org/10.1101/2020.12.16.423154; this version posted January 9.2022 . The copyright holder for this preprint (which was not certified by peer review) is the author/funder, who has granted bioRxiv a license to display the preprint in perpetuity. It is made available under aCC-BY-NC 4.0 International license.

\title{
A native chemical chaperone in the human eye lens
}

Eugene Serebryany ${ }^{1}$, Sourav Chowdhury ${ }^{1}$, Christopher N. Woods ${ }^{2}$, David C. Thorn ${ }^{1}$, Nicki E. Watson ${ }^{3}$, Arthur McClelland $^{3}$, Rachel E. Klevit ${ }^{2}$, and Eugene I. Shakhnovich ${ }^{1 *}$

${ }^{1}$ Department of Chemistry and Chemical Biology, Harvard University, Cambridge, MA, USA

${ }^{2}$ Department of Biochemistry, University of Washington, Seattle, WA, USA

${ }^{3}$ Center for Nanoscale Systems, Harvard University, Cambridge, MA, USA

* To whom correspondence should be addressed: shakhnovich@chemistry.harvard.edu

\section{Abstract}

Cataract is one of the most prevalent protein aggregation disorders and still the most common cause of vision loss worldwide. The metabolically quiescent core region of the human lens lacks cellular or protein turnover; it has therefore evolved remarkable mechanisms to resist light-scattering protein aggregation for a lifetime. We now report that one such mechanism involves an unusually abundant lens metabolite, myo-inositol, suppressing aggregation of lens crystallins. We quantified aggregation suppression using our previously well-characterized in vitro aggregation assays of oxidation-mimicking human $\mathrm{yD}$-crystallin variants and investigated myo-inositol's molecular mechanism of action using solution NMR, negative-stain TEM, differential scanning fluorometry, thermal scanning Raman spectroscopy, turbidimetry in redox buffers, and free thiol quantitation. Unlike many known chemical chaperones, myo-inositol's primary target was neither the native nor the unfolded state of the protein, nor the final aggregated state, but rather the rate-limiting bimolecular step on the aggregation pathway. Given recent metabolomic evidence that it is severely depleted in human cataractous lenses compared to agematched controls, we suggest that maintaining or restoring healthy levels of myo-inositol in the lens may be a simple, safe, and globally accessible strategy to prevent or delay lens opacification due to age-onset cataract.

\section{Introduction}

Cataract disease afflicts tens of millions of people per year and is the worldwide leading cause of blindness. ${ }^{1}$ The disease is caused by light-scattering aggregation of the extremely long-lived crystallin proteins in the lens. ${ }^{2}$ This aggregation is associated with accumulation of post-translational modifications, including disulfide formation, UV- or metal-catalyzed Trp oxidation, deamidation, Asp isomerization, Lys derivatization, truncation, and various others. ${ }^{3-5}$ Most age-onset cataract forms in the oldest, nuclear (or core) region of the lens. ${ }^{2}$ The cells in this region lack all organelles and thus protein synthesis and degradation capacity, and lens crystallins comprise $~ 90 \%$ of their protein mass. ${ }^{6}$ The most thermodynamically stable in humans is yD-crystallin ( $\mathrm{HyD}$ ), which, at neutral $\mathrm{pH}$, has a $\mathrm{T}_{\mathrm{m}}$ above $80^{\circ} \mathrm{C},{ }^{7}$ resistance to $8 \mathrm{M}$ urea, ${ }^{8}$ and unfolding half-life estimated to be on the order of decades. ${ }^{9}$ It is particularly abundant in the nuclear region of the lens and enriched in insoluble aggregates. ${ }^{3} \mathrm{HyD}$ consists of two homologous intercalated double-Greek key domains. The $\mathrm{N}$-terminal domain is less stable and derives part of its stability from the domain interface..$^{5,9} \mathrm{All} \mathrm{Y}$-crystallins are Cys-rich; ${ }^{10}$ thus, $\mathrm{HyD}$ contains six Cys residues, four of which are buried in the core of the N-terminal domain, yet there are no disulfides in the native state of the protein in vitro or in the young lens. ${ }^{7,11-13}$

In prior research, we have developed a physiologically relevant in vitro model of cataract-associated aggregation and investigated in molecular mechanistic detail the unfolding pathway and probable interactions involved. ${ }^{7,14-16}$ Mutations in HyD that cause congenital cataracts, including $\mathrm{W} 42 \mathrm{R},{ }^{17}$ cluster near the $\mathrm{N}$-terminal $\beta$-hairpin. ${ }^{5}$ The vast majority of cataracts arise not from congenital mutations but from age-related changes in the lens, including Trp oxidation in lens crystallins. ${ }^{4}$ We have shown that the oxidation-mimicking $W 42 Q$ variant and the congenital W42R produce similarly strong aggregation under physiologically relevant oxidizing conditions. ${ }^{16}$ The aggregates generated by the $\mathrm{W} 42 \mathrm{Q}$ variant, or by a variant at the cognate site in the $\mathrm{C}$-terminal domain (W130E), have been extensively characterized, making them well-suited for the present study. ${ }^{14-16}$ These variants are well-folded at $\mathrm{pH} 7$ and $37^{\circ} \mathrm{C}$, yet rare partially misfolded intermediates formed under those conditions, if locked by an internal disulfide bond, proceed to form aggregates. Since aggregation crucially depends non-native intramolecular disulfides, and due to latent oxidoreductase activity in $\mathrm{HyD}$ and likely other 
crystallins, this conformational transition from the native to the aggregation precursor state depends on the redox state of the crystallin proteome. ${ }^{7}$ These neutral-pH HyD aggregates do not stain with Thioflavin $\mathrm{T}$, indicating that they are not amyloid fibrils. ${ }^{14,15}$ This is consistent with electron microscopy of cataractous lens cytoplasm, which did not reveal any extended fibrillar structures. ${ }^{18,19}$ Others have also shown that crystallin aggregates induced by directly irradiating WT Y-crystallins with UV light are mostly (though not entirely) non-amyloid. ${ }^{20-22}$ The aggregates' binding to the surface hydrophobicity probe bis-ANS is also limited and occurs mostly at the earliest stages of aggregation. ${ }^{14,15}$ Therefore, the most experimentally tractable way of measuring the aggregation process is to measure light-scattering (solution turbidity) itself. This is also the most physiologically relevant metric since turbidity of the lens fiber cell cytoplasm is the main symptom of cataract. Fortunately, we have shown that solution turbidity is proportional to total mass for these aggregates ${ }^{15}$ and that simple power laws relate the aggregation rate and lag time to protein concentration, such that all aggregation traces collapse onto a single master curve, where all points that map onto a given master-curve point have the same particle size distribution. ${ }^{23}$

Despite intense research interest, ${ }^{24-26}$ no preventative or therapeutic drugs against cataract have been approved to-date, leaving surgery as the only treatment option. Aggregate costs of cataract surgery are high in high-income countries, ${ }^{27}$ while availability and outcomes are often poor in low- and middle-income ones. ${ }^{1,28}$ Hence, most cataract around the world remains untreated. ${ }^{29}$ Delaying the age of onset of the disease by $\sim 14 \%$ would cut the need for surgery by half by pushing the onset of blindness beyond the average lifespan. ${ }^{29}$

However, the search for cataract treatments has been hampered by three major challenges. Any such treatment must be (1) able to permeate into the nuclear region of the lens where most cataract occurs; (2) simple to use (e.g., eye drops) and extremely safe; and (3) sufficiently stable and cheap to be available to the vast majority of cataract patients who do not reside in high-income countries. ${ }^{30,31}$ The lens is a tightly packed tissue, and a diffusion barrier that forms during middle age prevents almost all externally applied compounds from penetrating into the lens nucleus. ${ }^{32}$ Unless a drug candidate lies within the highly constrained space of lenspermeating compounds, it is unlikely to be globally useful.

We therefore wondered whether the small molecule metabolome of the lens cytoplasm itself has evolved to produce or concentrate metabolites that suppress crystallin aggregation. Strong evolutionary pressure to preserve clear vision has produced multiple mechanisms to delay crystallin aggregation in the lens for as long as possible. Prior research focused largely on the crystallins themselves: the thermodynamic stability, kinetic stability, and redox activity of monomeric $\mathrm{y}$-crystallins; ${ }^{5,33}$ the stabilizing oligomerization and destabilizing deamidation of $\beta$-crystallins; ${ }^{34}$ and the passive chaperone role of $\alpha$-crystallins. ${ }^{35}$ Aggregation of crystallins, like that of many other proteins, can be modulated by osmolytes or other small metabolites. ${ }^{36,37}$ Metabolomic analyses showed certain small metabolites to be unusually abundant in the lens, notably myo-inositol, ${ }^{38,39}$ which, however, is greatly depleted in cataractous lenses. ${ }^{39,40}$ We now report that myo-inositol (commonly referred to as just "inositol," since it is the naturally prevalent isomer) acts as a kinetic inhibitor of the aggregation of the oxidation-mimicking, cataract-associated W42Q variant of human yD-crystallin, as well as other variants that aggregate under physiologically relevant oxidizing conditions. Notably, this compound slows the aggregation rate even when added at a later stage in the aggregation process. We show that inositol inhibits the rate-limiting bimolecular step in the aggregation pathway, and thereby indirectly disfavors the non-native disulfide bonds that stabilize the aggregation precursor. As one of the very few molecules known to permeate into the lens from the outside, by both passive and active transport, ${ }^{41,42}$ myo-inositol therefore has the potential to become a safe, simple, and globally accessible treatment to prevent or delay loss of vision due to age-onset cataract disease.

\section{Results}

Inositol suppresses aggregation of cataract-associated $\gamma D$-crystallin variants

We tested a variety of sugars and sugar alcohols for their ability to suppress aggregation of W42Q HyD as the in vitro model of cataract-associated aggregation. Figure 1A shows a representative set of normalized turbidity traces demonstrating strong and dose-dependent suppression of turbidity development by myo-inositol. As shown in Figure 1B, even highly similar compounds, at $100 \mathrm{mM}$ each, had widely varying effects, from strong suppression to moderate enhancement of aggregation. Solution turbidity at the end of the $4.5 \mathrm{~h}$ incubation was measured in 96-well plates and the turbid solutions then clarified by centrifugation. Consistent with prior studies (see above), the amount of residual protein in the clarified supernatant had a strong linear inverse correlation 
bioRxiv preprint doi: https://doi.org/10.1101/2020.12.16.423154; this version posted January 9, 2022. The copyright holder for this preprint (which was not certified by peer review) is the author/funder, who has granted bioRxiv a license to display the preprint in perpetuity. It is made available under aCC-BY-NC 4.0 International license.

with end-point solution turbidity, suggesting that these compounds inhibited the aggregation process without changing aggregate shape or size. The linear correlation between turbidity and aggregate mass further validated the use of turbidity as a quantitative measure of this particular aggregation process. The concentrations of compounds used here were not high enough to alter bulk solution properties (Figure 1-supplement 1).

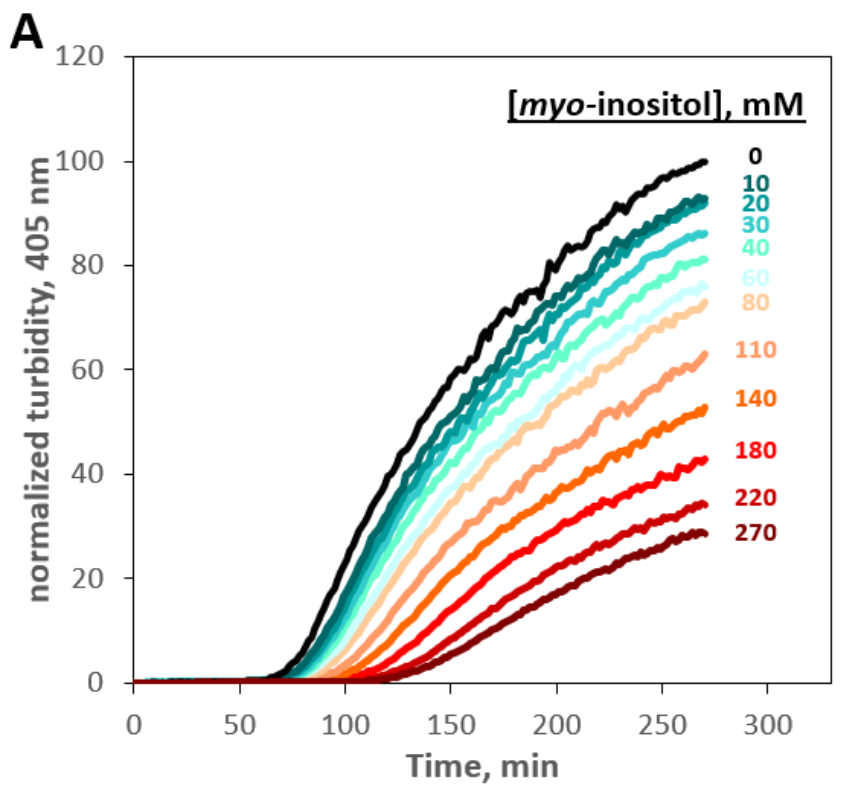

C

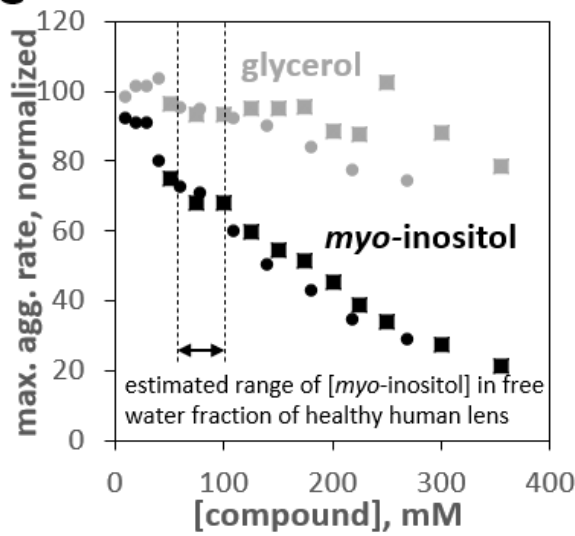

B

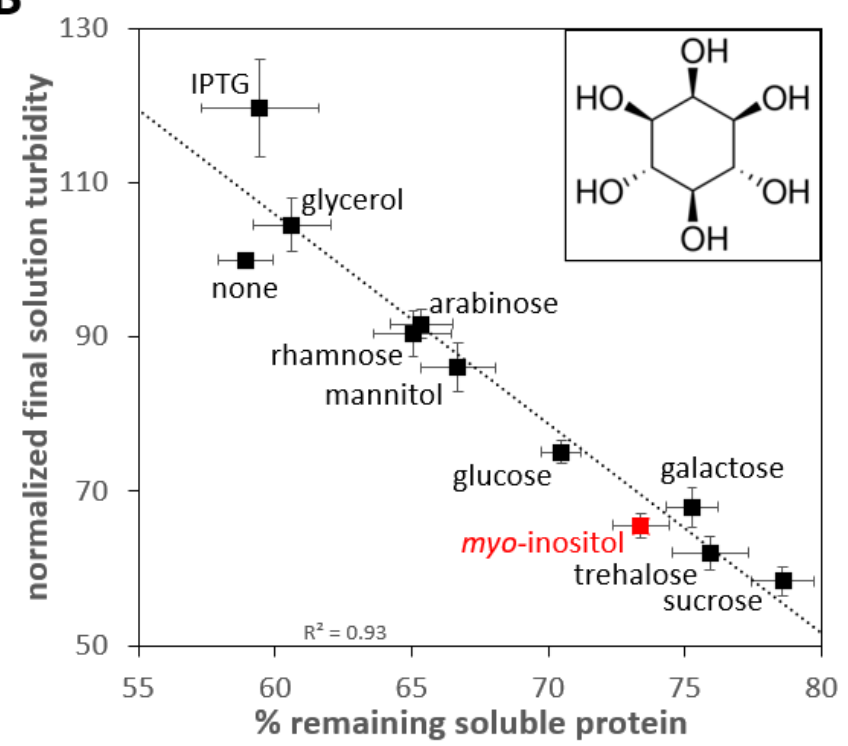

E

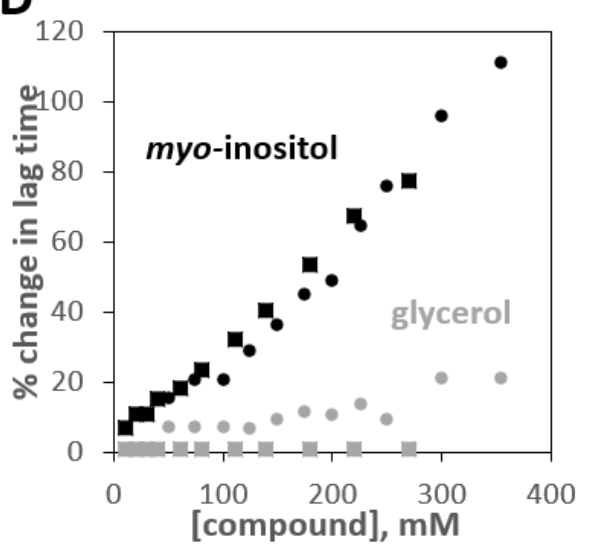

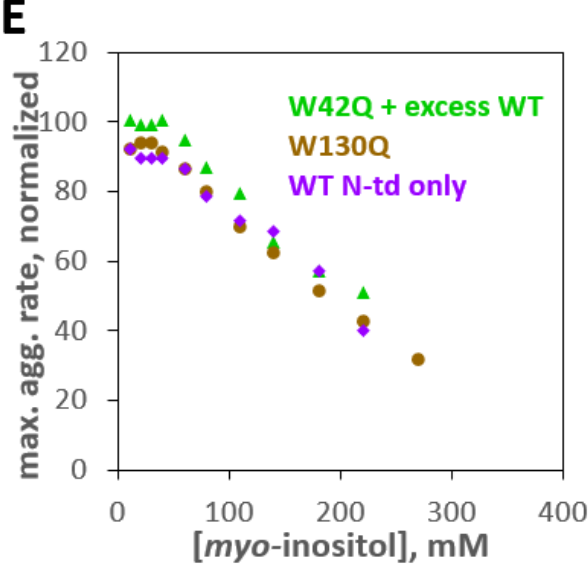

Figure 1: Suppression of human YD-crystallin aggregation by myo-inositol. Oxidative aggregation of the cataractmimicking W42Q variant of $\mathrm{HyD}$ was initiated as previously described. ${ }^{7}$ (A) Normalized turbidity traces for the oxidative aggregation of $40 \mu \mathrm{M} \mathrm{HyD} \mathrm{W42Q}$ with varying concentrations of myo-inositol. (B) Sugars and sugar alcohols, each at 100 $\mathrm{mM}$, suppressed HyD W42Q aggregation to varying degrees. Isopropyl- $\beta$-D-thiogalactoside (IPTG) moderately enhanced turbidity development. Myo-inositol (structure shown in inset) consistently and strongly suppressed turbidity development, second only to the disaccharides, trehalose and sucrose. A total of 8 independent replicates, at pH 7.4 (HEPES), pH 6.7 (PIPES), or pH 6.0 (MES) and $150 \mathrm{mM} \mathrm{NaCl}$ all produced similar results and were averaged together. Notably, the strong linear correlation between reduction in solution turbidity and increase in the proportion of protein remaining soluble indicated these compounds (except perhaps IPTG) did not significantly change aggregate geometry. (C) Dose response for aggregation suppression by myo-inositol compared to glycerol. Notably, myo-inositol had a significant effect in the physiological concentration range. Data from two independent replicates (circles, squares) are shown; black circles correspond to the data in panel A. All aggregation rates were normalized to the rate without myo-inositol. (D) Percent change in aggregation lag time for the same experiments as in Panel C. (E) Suppression of oxidative aggregation by myo-inositol generalizes to other HyD constructs: Green triangles, $20 \mu \mathrm{M} \mathrm{W} 42 \mathrm{Q}$ whose aggregation is catalyzed by $180 \mu \mathrm{M}$ WT HyD at $37{ }^{\circ} \mathrm{C}$; Beige circles, $40 \mu \mathrm{M} \mathrm{W130Q}$ at $42^{\circ} \mathrm{C}$; Purple diamonds, $50 \mu \mathrm{M}$ wild-type isolated N-terminal domain of $\mathrm{HyD}$ at 44 ${ }^{\circ} \mathrm{C}$. All experiments were carried out in $10 \mathrm{mM}$ PIPES pH 6.7, $150 \mathrm{mM} \mathrm{NaCl}, 1 \mathrm{mM}$ EDTA, with $0.5 \mathrm{mM}$ GSSG as the oxidant.

That the ability to suppress crystallin aggregation varied among chemically similar compounds strongly suggests specific protein-metabolite interactions. Thus, myo-inositol was much more effective than mannitol -a sugar alcohol with the same number of carbons and hydroxyls but a linear rather than cyclic structure. Galactose was one of the strongest aggregation suppressors, yet its derivative IPTG enhanced aggregation. 
bioRxiv preprint doi: https://doi org/10.1101/2020.12 16.423154; this version posted January $9,2022$. The copyright holder for this preprint (which was not certified by peer review) is the author/funder, who has granted bioRxiv a license to display the preprint in perpetuity. It is made available under aCC-BY-NC 4.0 International license.

Figure 1C shows a more detailed comparison of dose-response curves for myo-inositol and glycerol. Tsentalovich et al. reported $24.6 \pm 6.7 \mu \mathrm{mol}$ of myo-inositol per gram of wet lens in the nuclear region, dropping to just $1.9 \pm 1.8 \mu \mathrm{mol} / \mathrm{g}$ in the nuclear region of cataractous lenses. ${ }^{39}$ Assuming a water content of $\sim 60 \%$ and a total of $\sim 50 \%$ of the water in a bound state, per a prior study, ${ }^{43}$ we arrive at an estimate of $82 \pm 22 \mathrm{mM}$ myoinositol in the free water fraction of the healthy human lens. In this concentration range, myo-inositol already had a substantial effect in our assay, suppressing the rate of turbidity development by $\sim 35 \%$ and increasing the lag time by a similar amount (Figure 1D), consistent with the "master curve" relationships between maximum rate, lag time, and endpoint turbidity. ${ }^{23}$ It has been estimated that delaying the age of onset of cataract by $14 \%$ would halve the global disease burden; ${ }^{29}$ conversely, the near-complete loss of myo-inositol in cataractous lenses ${ }^{39,40}$ could be a major factor increasing that burden. Less-abundant lens metabolites, including scyllo-inositol and glucose, likely contribute to aggregation suppression. Glycerol, previously shown to be also abundant in the lens, ${ }^{38}$ was much less effective. Scyllo-inositol offered no advantage over myo-inositol (Figure 1-supplement 2) and was not pursued further owing to its lower solubility and higher cost.

We next checked whether aggregation suppression was broadly effective or specific to the W42Q HyD variant. Dose-dependent suppression of oxidative aggregation was observed in a variety of aggregation-prone HyD constructs. We have previously found that, while the $W 42 Q$ variant aggregates on its own at sufficient concentrations, the wild-type protein promotes $\mathrm{W} 42 \mathrm{Q}$ aggregation without itself aggregating. ${ }^{7,15}$ Figure 1E shows that aggregation of low [W42Q] in the presence of high [WT] was also suppressed by myo-inositol. The W130Q variant, which mimics oxidation of the cognate tryptophan in the C-terminal domain, was likewise rescued. The $\mathrm{N}$-terminal domain of $\mathrm{H} y \mathrm{D}$ derives part of its stability from the domain interface (which may be disrupted over time, e.g., by deamidation or truncation ${ }^{44,45}$ ), so the isolated domain forms aggregates at slightly elevated temperatures with oxidation. ${ }^{23}$ Inositol suppressed aggregation of the wild-type $\mathrm{N}$-terminal domain of $\mathrm{HyD}$ ("N-only") like that of the other variants. Aggregation of $\mathrm{N}$-only and W130Q, like that of W42Q, was entirely redox-dependent (Figure1-supplement 3), so the aggregation precursor conformations adopted by all these variants are likely kinetically trapped by non-native disulfide bonds. Since the two Cys residues forming the most aggregation-favoring disulfide (Cys32 and Cys41) are highly conserved among $Y$-crystallins, ${ }^{10}$ we expect that this aggregation pathway is typical for the $\mathrm{Y}$-crystallin family and predict that myo-inositol and its isomers and derivatives suppress aggregation of other $\gamma$-crystallins, whether they are damaged by mutations or by covalent side-chain modifications or backbone truncations accumulated during the course of aging. The rest of our study concerns the mechanism of aggregation suppression by myo-inositol.

Inositol neither binds the native state nor destabilizes the unfolded state

The effects of chemical chaperones (protective osmolytes) on proteins are typically conceptualized as increasing the protein's thermodynamic stability, either by stabilizing the native state via a binding interaction or by destabilizing the unfolded state via preferential protein backbone exclusion. ${ }^{46-48}$ We obtained ${ }^{1} \mathrm{H}-{ }^{15} \mathrm{~N} \mathrm{HSQC}$ NMR spectra of WT and W42Q HyD at $37^{\circ} \mathrm{C}$ with and without $100 \mathrm{mM}$ inositol (Figure 2A,B). This inositol concentration is in the estimated physiological range and clearly suppresses aggregation (see above). From the underlying data of Figure $1 \mathrm{~A}, \mathrm{~B}$, we calculated maximum aggregation rate suppression of $35 \pm 3 \%$ (mean \pm S.E.M. of 4 experiments). Yet, the NMR spectra for each protein with and without inositol were superimposable; thus, we found no defined binding interaction between inositol and the native structure of HyD WT or W42Q.

If myo-inositol's effect were achieved by destabilizing the unfolded state, then it would increase native thermodynamic stability even without binding the native state. To improve assignment of unfolding transitions, we measured thermal stability for each HyD domain separately as a function of [inositol] by differential scanning fluorometry (DSF) with SYPRO Orange as the hydrophobicity probe (Figure 2C,D). Only very minor stabilization was observed (up to $\sim{ }^{\circ} \mathrm{C}$ at the highest [inositol]) - not sufficient to account for the aggregation suppression.

If inositol were to bind and stabilize a partially unfolded state, it would decrease the native state's stability. This was not observed. Nevertheless, since the DSF traces were silent at the N-terminal domain's aggregationpermissive temperature $\left(44^{\circ} \mathrm{C}\right.$ in Figure 1E), we sought a more sensitive measurement of any structural changes in that range. We therefore constructed a thermal scanning Raman spectroscopy apparatus (schematized in Figure 2E). Protein solutions in sealed vessels (to avoid evaporation) were placed under a Raman microscope. We scanned the entire amide I region $\left(1600\right.$ to $\left.1700 \mathrm{~cm}^{-1}\right)$, which reports mostly $(70-85 \%)$ the $\mathrm{C}=\mathrm{O}$ stretch, with a smaller contribution from the $\mathrm{C}-\mathrm{N}$ stretch, and is therefore an excellent probe of protein secondary structure..$^{49,50}$ Overall signal strength is a rough measure of foldedness. 

available under aCC-BY-NC 4.0 International license.
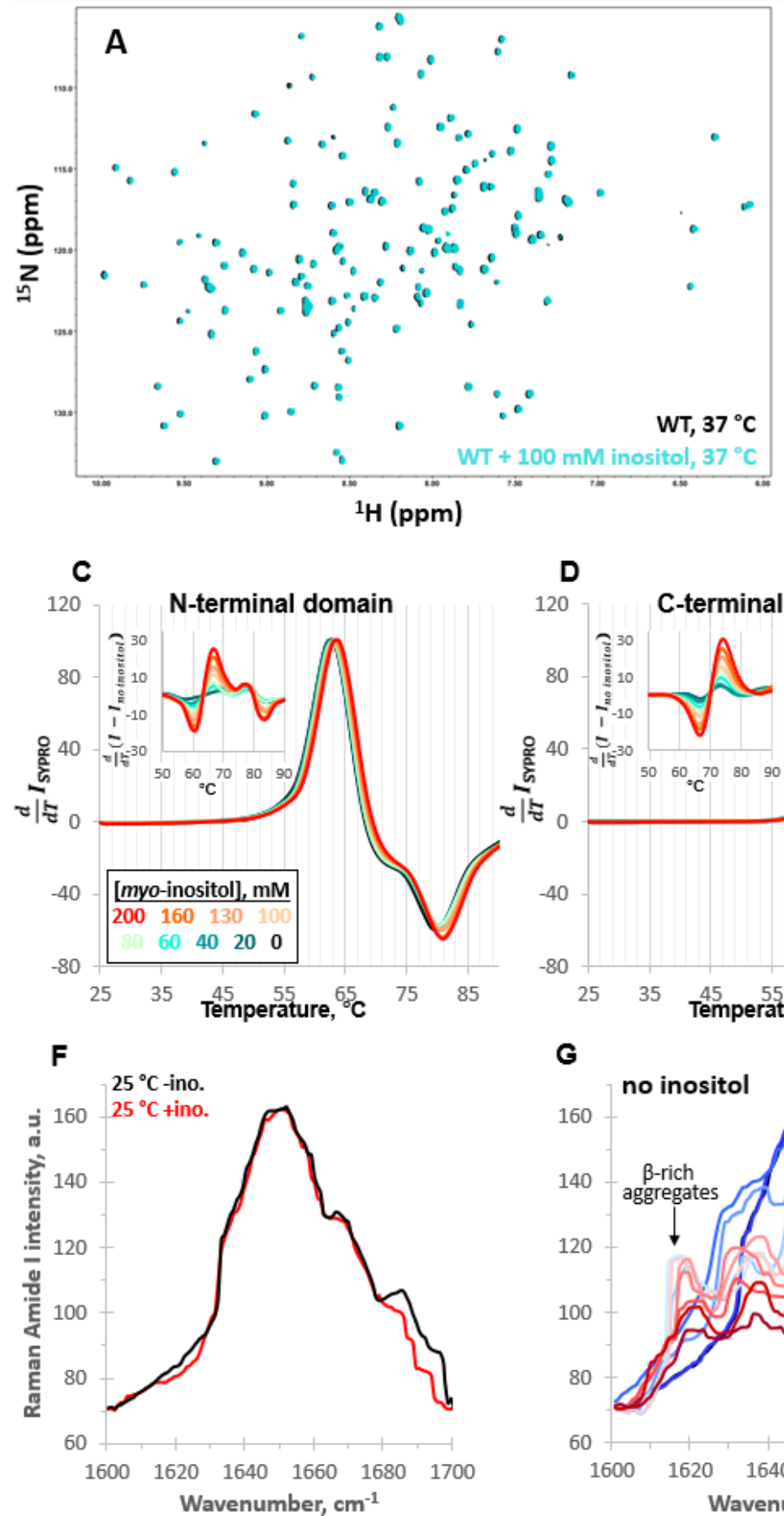
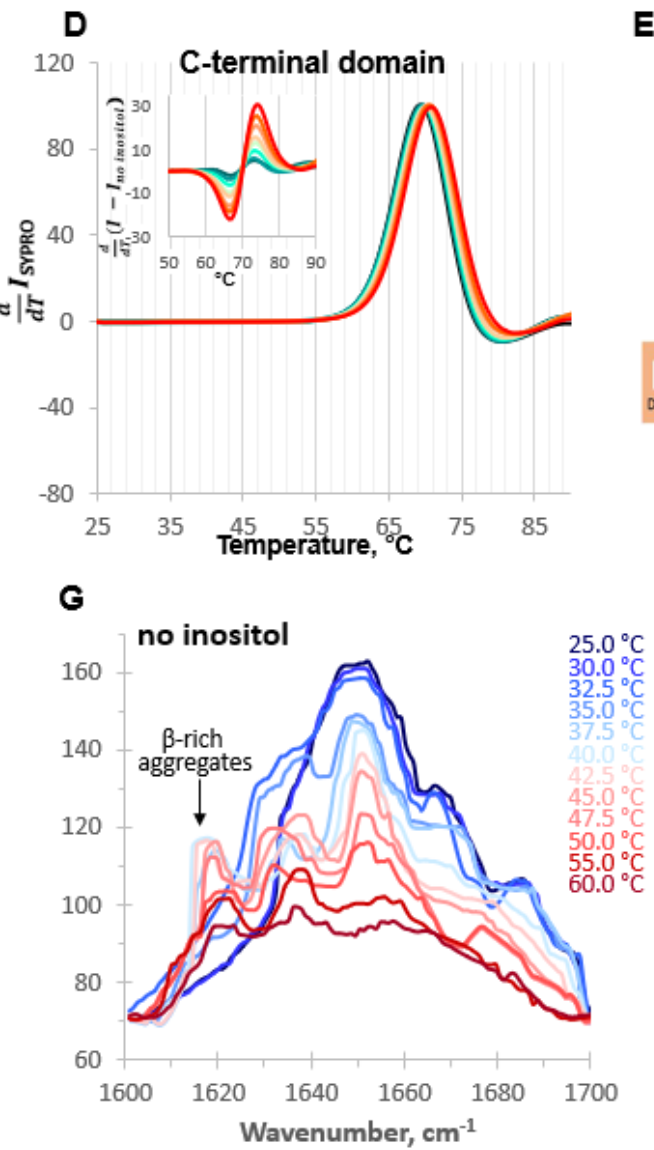

E
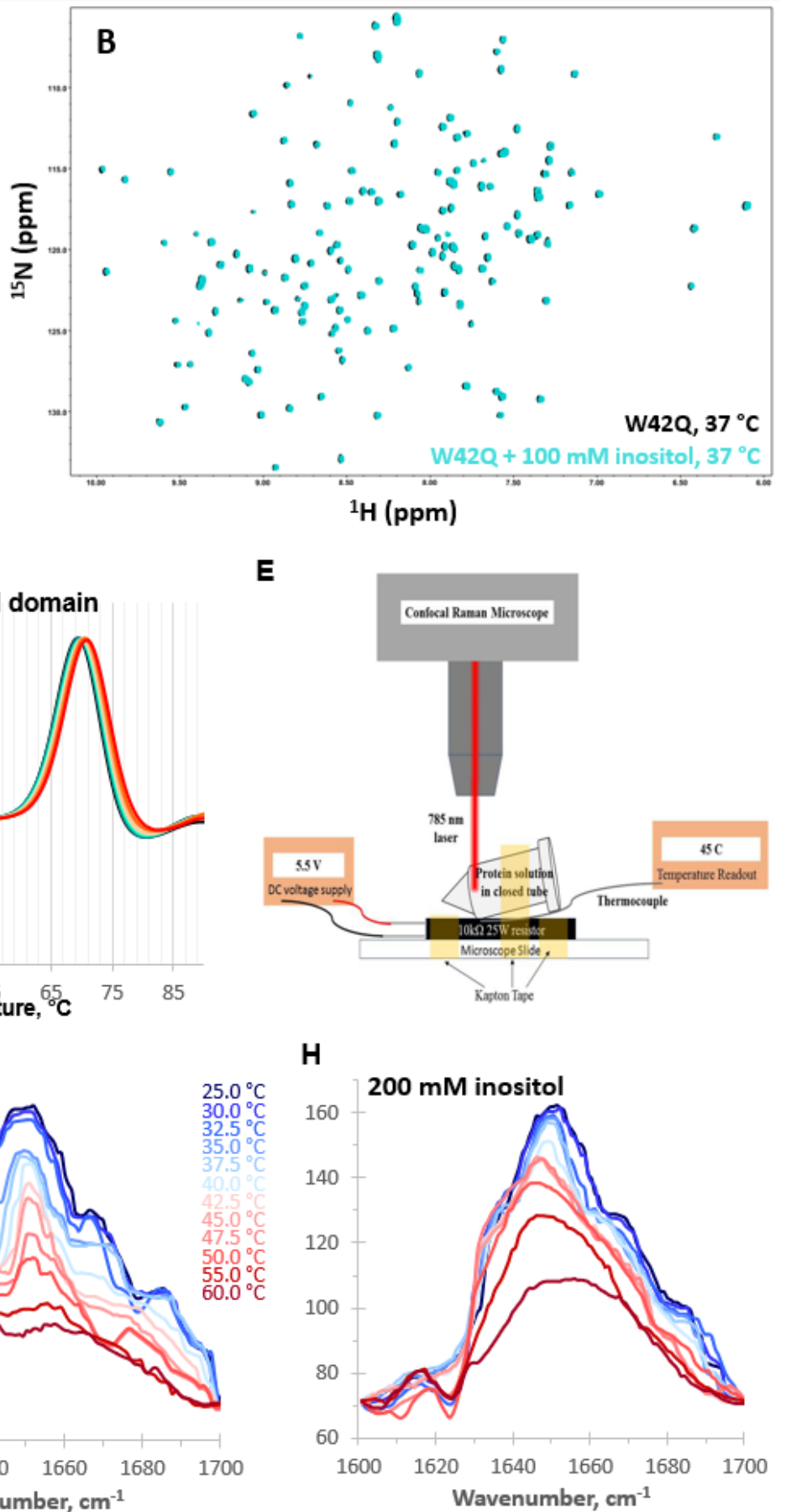

Figure 2: Myo-inositol has no effect on the native structure and only minor effects on stability. (A, B) ${ }^{1} \mathrm{H}-{ }^{15} \mathrm{~N} \mathrm{HSQC}$ NMR spectra of full-length WT and W42Q HyD at $37^{\circ} \mathrm{C}$ show no evidence of interaction between myo-inositol and the protein's native structure. (C, D) Differential scanning fluorometry with SYPRO Orange as the hydrophobicity probe revealed no change within the temperature range of aggregation but very small dose-dependent shifts toward higher melting temperatures. Normalized first derivative curves of SYPRO Orange fluorescence intensity are shown for both the $\mathrm{N}$ - and C-terminal domains, where peak positions correspond to $T_{m}$; insets show the difference curves. (E) Schematic of the design of the thermal scanning Raman spectroscopy apparatus. (F) Raman Amide I band spectra of the isolated Nterminal domain were likewise overlapping at low temperatures. (G, H) At 32.5 and $35.0^{\circ} \mathrm{C}$ without inositol, a $\beta$-sheet peak $\sim 1630 \mathrm{~cm}^{-1}$ became prominent, while a $\sim 1620 \mathrm{~cm}^{-1}$ peak, typical of $\beta$-sheet-rich aggregates, was observed above $35.0^{\circ} \mathrm{C}$. Both features were strongly suppressed by $200 \mathrm{mM}$ inositol.

Even at $200 \mathrm{mM}$ [myo-inositol], the Amide I spectra of $\mathrm{N}$-only at $25{ }^{\circ} \mathrm{C}$ with and without inositol overlapped, except for a very small feature at $\sim 1690 \mathrm{~cm}^{-1}$ that could not be confidently assigned (Figure 2F), and the calculated secondary structure content under both conditions matched the PDB reference structure (Figure 2-supplement 1). Temperature was then gradually ramped from 25 to $60{ }^{\circ} \mathrm{C}$ to investigate the early unfolding transitions (Figure 2G,H). In this experiment, inositol clearly suppressed conformational change in the 
bioRxiv preprint doi: https://doi org/10.1101/2020.12.16.423154; this version posted January $9,2022$. The copyright holder for this preprint (which was not certified by peer review) is the author/funder, who has granted bioRxiv a license to display the preprint in perpetuity. It is made available under aCC-BY-NC 4.0 International license.

sample, ${ }^{51}$ notably the emergence of a $\sim 1620 \mathrm{~cm}^{-1}$ peak (Figure $2 \mathbf{G}$ ), which was attributable to $\beta$-sheet-rich aggregates. ${ }^{52}$ Sample with inositol, by contrast, lost signal intensity in smooth progression during the temperature ramp (Figure $\mathbf{2 H}$ ), indicating loss of structure without misfolding. A distinct feature in the $\beta$-sheet range, ${ }^{53}$ at $\sim 1630 \mathrm{~cm}^{-1}$, became prominent in the absence of inositol at $\mathrm{T}=32.5$ and $\mathrm{T}=35^{\circ} \mathrm{C}$, before the $\sim 1620 \mathrm{~cm}^{-1}$ peak emerged, raising the possibility that these were early-stage aggregates or precursors that inositol suppressed.

\section{Inositol produces only subtle changes in aggregate morphology and particle size distribution}

We used negative-stain transmission electron microscopy to investigate the effect of myo-inositol on the aggregation process. Notably, even the control sample contained a small number of large condensed aggregate particles (Figure 3A); these particles form during storage and incubation without reducing agent and contribute very little to overall turbidity. Samples from the turbid solutions (Figure 3B,C) showed much greater texturing on the survey micrographs and were replete with smaller aggregates. Figure 3D-G show representative images of the observed types of aggregates and suggest a sequence of structural transitions on the way to the insoluble aggregated state (Figure 3H). Myo-inositol produced no qualitative change in the morphology of the aggregates.

We next carried out morphometry of the aggregates, using a total of 103 separate images from duplicate aggregated samples with 0,100 , or $250 \mathrm{mM}$ myo-inositol. A double-blind was set up to minimize human bias: the microscopist did not know which sample came from which treatment condition, and the image analyst did not know which images came from which sample. Aggregates were visually classified into globular/collapsed or extended/fibril-like based on whether a curve could be clearly traced from one end to the other; aggregates composed of multiple extended chains or featuring intra-chain interactions that obscured one or both ends were considered globular. For this reason, the extended aggregates were typically short in length.

We used two alternative quantification approaches: the size distributions of particles ranked from largest to smallest (Figure 4A,D) and statistics of the size and number of aggregates of either type by image (Figure 4B,C;E,F). Inositol-induced changes in aggregate size distributions were minor but mechanistically informative. At the intermediate, near-physiological concentration $(100 \mathrm{mM})$, the extended aggregates became shorter and the globular ones fewer in number. By contrast, globular aggregates in the intermediate range (rank $~ 25-55$ in Figure 4D) grew slightly larger than without the inhibitor. By contrast, at the high myo-inositol concentration (250 $\mathrm{mM}$ ), the extended aggregates lengthened slightly compared to the no-inositol control (Figure 4A), yet the larger, globular aggregates shrank across the board (Figure 4D) and covered significantly less total grid area per image (Figure 4E). The shapes of the size distributions for the globular aggregates under the three treatment conditions (Figure 4D) were compared by two-sided Kolmogorov-Smirnov tests. These tests indicated statistically likely differences between 0 and $100 \mathrm{mM}$ myo-inositol $(\mathrm{p}=0.0032)$ and between 100 and $250 \mathrm{mM}$ myo-inositol $(p=$ 0.0048). The shapes of the aggregate size distributions at 0 and $250 \mathrm{mM}$ myo-inositol were not statistically distinct $(p=0.22)$, though the distribution of aggregate sizes at $250 \mathrm{mM}$ was clearly shifted downward.

While myo-inositol did not appreciably alter overall aggregate morphology, the more subtle shifts in aggregate size distributions presented a seeming paradox. At $100 \mathrm{mM}$, the compound reduced the number and size of smaller aggregates but not of larger ones, while at $250 \mathrm{mM}$ it decreased the size of the larger aggregates more than the smaller ones (indeed, the extended aggregates appeared to lengthen). We can rationalize this behavior by observing that large globular aggregates frequently contained internal cavities, which suggests they formed via condensation and coalescence of smaller ones (Figure $3 \mathbf{H}$ ). Myo-inositol may slow the earliest steps of aggregate assembly, up to the formation of short extended chains, which assemble predominantly one proteinprotein interaction at a time. Collapse and coalescence of the small aggregates involve many protein-protein interactions simultaneously, and the high avidity of interactions, along with possible formation of rare intermolecular disulfides, could overcome the aggregation suppression by low or intermediate [myo-inositol]. High [myo-inositol], however could slow down the early aggregation steps to such a degree as to effectively shift the entire aggregate size distribution to an earlier point on the aggregation master curve, consistent with the increased lag time (Figure 1A,D). Essentially, the largest aggregates may not have had time to form by the endpoint of the assay, leaving a relatively larger proportion of the aggregates small.

Although $100 \mathrm{mM}$ inositol (1.8\% w/v) did not change bulk solvent properties (Figure 1-supplement 1), we found that the solubility limit of myo-inositol was $\sim 500 \mathrm{mM}$ in water or aqueous buffer, so concentrations in the high-millimolar or molar range could not be assayed. Complete numerical data on the aggregate particle size distributions are tabulated in Figure 4-supplement 1. 
bioRxiv preprint doi: https://doi.org/10.1101/2020.12.16.423154; this version posted January 9, 2022. The copyright holder for this preprint (which was not certified by peer review) is the author/funder, who has granted bioRxiv a license to display the preprint in perpetuity. It is made available under aCC-BY-NC 4.0 International license.
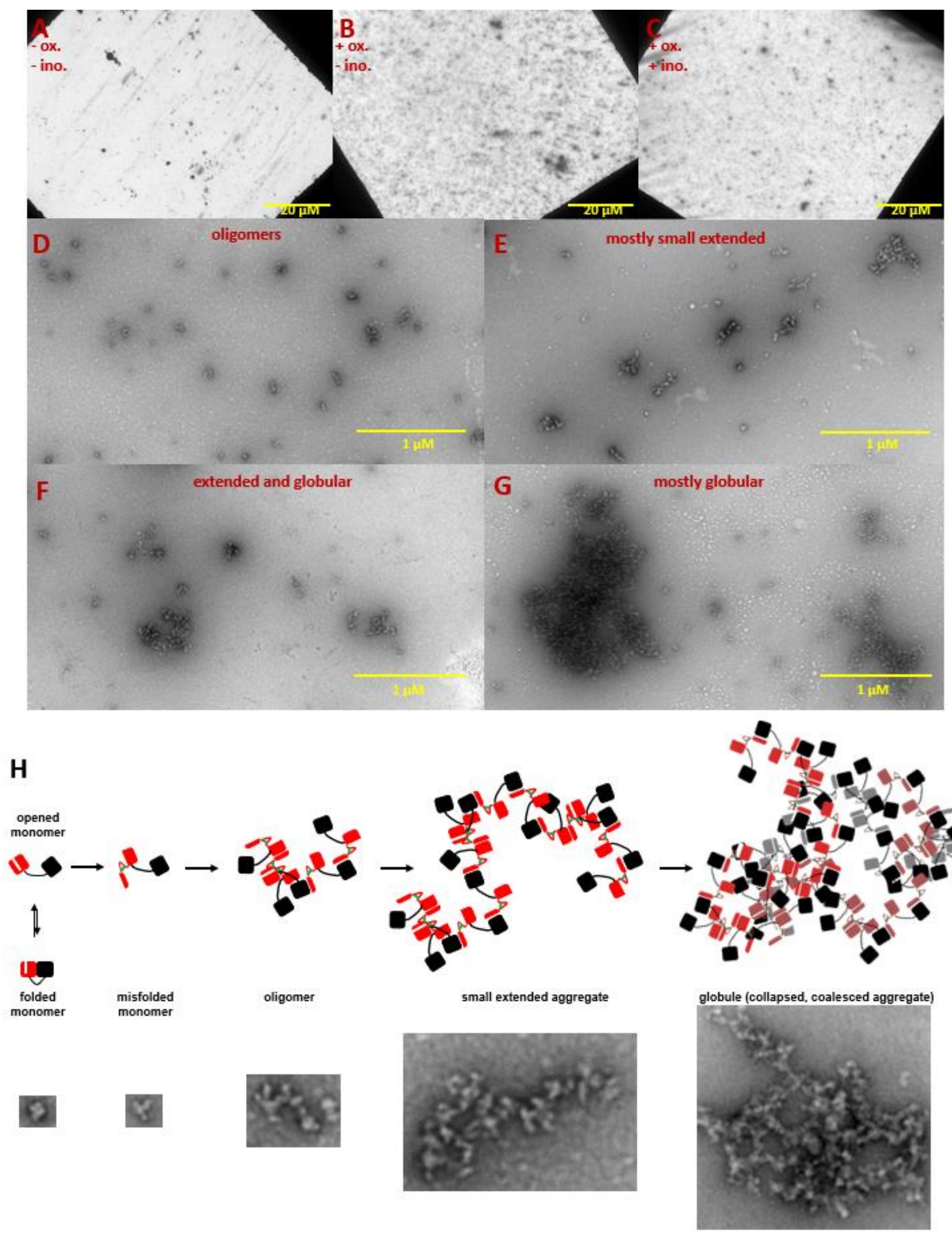

Figure 3: Negative-stain TEM images of HYD W42Q aggregates reveal short fibrillar and large globular structures. Aggregation of $40 \mu \mathrm{M}$ protein in pH 6.7 PIPES buffer with $150 \mathrm{mM} \mathrm{NaCl}$ and $1 \mathrm{mM}$ EDTA was triggered by addition of oxidant ( $0.5 \mathrm{mM} \mathrm{GSSG})$ and incubation at $37^{\circ} \mathrm{C}$ for $4 \mathrm{~h}$. End-point samples were deposited on carbon-coated copper grids and stained with uranyl acetate. The top row shows survey images of whole grids for $(A)$ control sample incubated in the absence of GSSG; (B) turbid sample in the presence of GSSG; and (C) turbid sample in the presence of GSSG and $100 \mathrm{mM}$ myo-inositol. Panels D-G show the variety of aggregate morphologies observed in representative magnified images from these grids, with (D) showing mostly small oligomers (not counted as aggregates in Figure 4); (E) showing mostly small extended aggregates; $(F)$ showing extended aggregates in the process of collapsing and coalescing; and (G) showing highly coalesced globular aggregates; $(\mathrm{H})$ Graphical model of HyD aggregation and its suppression by myoinositol: aggregation begins with oxidative misfolding of a mutant or damaged protein, as we have previously found, ${ }^{16}$ followed by assembly of short extended chains via domain swap-like interactions, ${ }^{7,16}$ and finally coalescence to globular particles. Examples of TEM evidence of each type of structure in this study are shown in the bottom row (not all to scale). 
bioRxiv preprint doi: https://doi.org/10.1101/2020.12.16.423154; this version posted January 9,2022 . The copyright holder for this preprint (which was not certified by peer review) is the author/funder, who has granted bioRxiv a license to display the preprint in perpetuity. It is made available under aCC-BY-NC 4.0 International license Globular aggregates
gregates
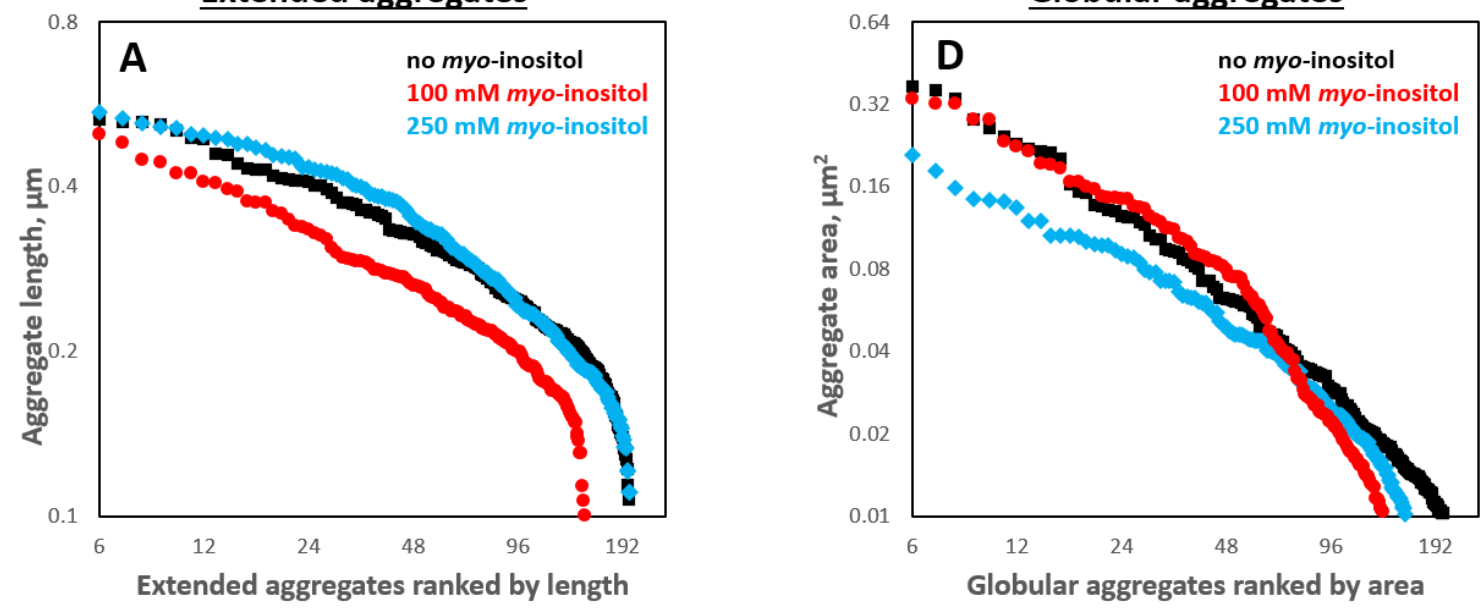

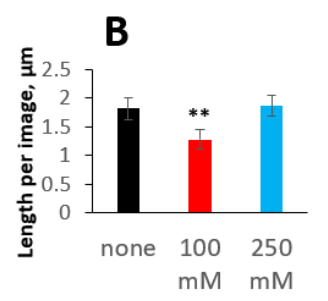

[myo-inositol]

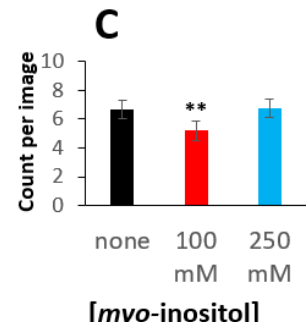

[myo-inositol]

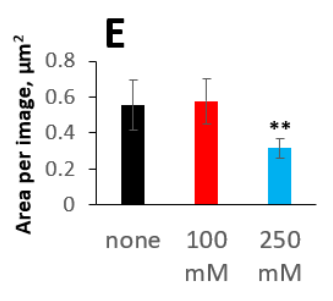

[myo-inositol]

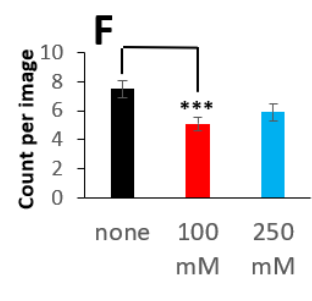

[myo-inositol]

Figure 4: Myo-inositol produces only modest shifts in the aggregate particle size distribution. Aggregates generated as in Figure 1 in the presence of 0 , intermediate $(100 \mathrm{mM})$ or high $(250 \mathrm{mM})$ myo-inositol were imaged and analyzed by negative-stain transmission electron microscopy (Figure 3) in a double-blinded procedure, with a total of 103 separate images used for analysis. Aggregates were classified by inspection into extended (irregular fibrils) vs. globular (collapsed/coalesced) based on whether a curve could be unambiguously traced from end to end. (A, B, C) $100 \mathrm{mM}$ myoinositol decreased both the number and the length of extended aggregates, but $250 \mathrm{mM}$ myo-inositol did not. Error bars represent S.E.M. of particle counts and their combined lengths per image. (D, E, F) $100 \mathrm{mM}$ myo-inositol depleted the smallest globular aggregates, slightly increased the size of intermediate ones, and left the largest ones unchanged, but 250 $\mathrm{mM}$ myo-inositol reduced the size of the largest aggregates.

Inositol inhibits the rate-limiting bimolecular step and slows formation of disulfide-trapped aggregation precursors

The redox potential of lens fiber cell cytoplasm becomes progressively more oxidizing with age. ${ }^{10}$ While all experiments in Figures 1-4 were carried out in fully oxidizing buffers (0.5 mM GSSG), we have previously shown that $\mathrm{W} 42 \mathrm{Q}$ and $\mathrm{W} 42 \mathrm{R}$ aggregation proceeds in the physiologically relevant range of redox-coupled buffers. ${ }^{16}$ Myo-inositol is redox-inert, but we nonetheless investigated whether its aggregation suppressing effect was affected by the degree of oxidation of the buffer. We defined degree of oxidation (OxD) as it was used by Romero-Aristizabal et al., ${ }^{54}$ as follows:

$$
\mathrm{OxD}=\frac{2[\mathrm{GSSG}]}{([\mathrm{GSH}]+2[\mathrm{GSSG}])}
$$

Note that the true redox potential of the buffer depends not only on OxD but also on the total concentration of glutathione, since the formation of glutathione disulfide is bimolecular. ${ }^{54}$ We used physiologically plausible total glutathione of $2 \mathrm{mM}$ in most of the following experiments, except in Figure 6A,B as noted.

As shown in Figure 5, aggregation at OxD 0.15 to 0.40 was OxD-dependent but always more strongly suppressed by inositol than in the fully oxidizing buffers (Figure 1A,B). (Overall, the aggregation propensity in these experiments was higher than in our previous study; ${ }^{16}$ this difference is attributable to higher buffer ionic strength.) Suppression of maximum aggregation rate did not vary significantly among this series of redox buffers; we observed maximum aggregation rate suppression of $51 \pm 2 \%$ (mean \pm S.E.M. for the six redox buffers), significantly greater than the $35 \pm 3 \%$ obtained from the fully oxidizing buffers (Figure 1). By contrast, the apparent aggregation lag times significantly longer at low OxD values in the presence of inositol (Figure 5C,D). This was consistent with the above findings that inositol suppressed an early stage of aggregate formation. In fact, low OxD combined with $100 \mathrm{mM}$ inositol slowed early (but not late) aggregate assembly so much that turbidity traces became visibly biphasic (Figure 5B). Since both the maximum rate and the lag time were calculated from the second phase (see Figure 6-supplement 2 for illustration), the apparent lag times became significantly longer. 
bioRxiv preprint doi: https://doi.org/10.1101/2020.12.16.423154; this version posted January 9 , 2022. The copyright holder for this preprint (which was not certified by peer review) is the author/funder, who has granted bioRxiv a license to display the preprint in perpetuity. It is made available under aCC-BY-NC 4.0 International license.

A

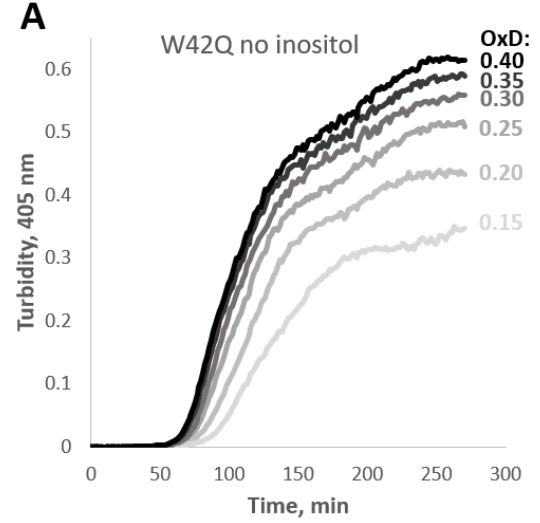

B

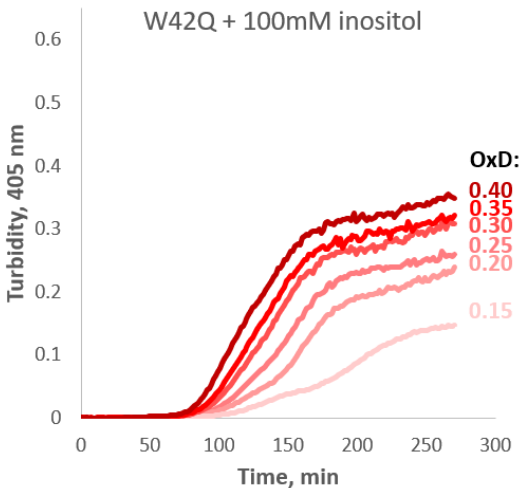

C

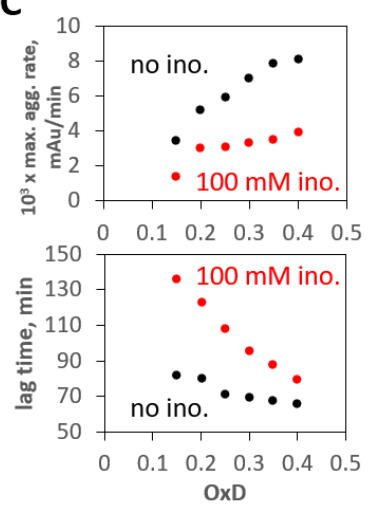

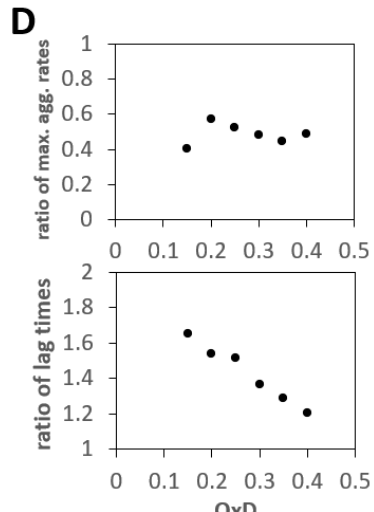

OxD

Figure 5: Myo-inositol suppresses aggregation more strongly in redox buffers. (A, B) Turbidity traces of $50 \mu \mathrm{M}$ W42Q in buffers with set redox potentials using the glutathione redox couple, where OxD = 2[GSSG]/([GSH]+2[GSSG]), and $([G S H]+2[G S S G])=2 m M$ in all cases. The OxD range shown is consistent with what is observed during cataract development. ${ }^{4}$ Notably, in the least-oxidizing buffers with myo-inositol, the turbidity curves became biphasic. (C) Quantification of the maximum aggregation rates and lag times for the curves in $(A)$ and $(B)$ showed stronger aggregation suppression by $100 \mathrm{mM}$ myo-inositol than in Figure 1A,B. (D) Ratios of maximum aggregation rates (+inositol/-inositol) $($ top) and aggregation lag times (bottom), for the data shown in panel (C). Averaged across the OxD buffers, mean \pm S.E.M. for inositol's inhibitory effect on the aggregation rate was $51 \pm 2 \%$ vs. $35 \pm 3 \%$ observed in the fully oxidizing buffer.

We have previously shown that, while aggregation requires disulfide-trapped misfolding of the $\mathrm{N}$-terminal domain, the two Cys residues in HyD's C-terminal domain, which are not directly involved in the aggregation process, constitute an oxidoreductase site. ${ }^{7}$ To investigate the effect of inositol on the redox state distribution most relevant to the aggregation process, we removed the oxidoreductase site from the W42Q variant, generating the triple-variant W42Q/C108S/C110S. End-point samples of W42Q/C108S/C110S aggregates at various OxD's were then reacted with PEG5000-conjugated maleimide. The gel shifts due to the PEGylation are an excellent reporter of the redox state distribution because, unlike the commonly used Ellman assay, they report not just the average number of free thiols per molecule but the relative abundances of protein molecules by number of free thiol groups per molecule. ${ }^{7}$ Since the maleimide group needed to be in excess of thiols to ensure complete labeling, total glutathione was lowered to $0.5 \mathrm{mM}$ for these experiments. Under those conditions, 200 $\mathrm{mM}$ inositol suppressed aggregation almost completely (Figure 6A).

In the more mildly oxidizing buffers (OxD' 0.15 or 0.20 ), a clear shift in the redox state distribution was observed in the presence of inositol (Figure 6B). The quadruply-PEGylated band, which corresponds to fully reduced protein, became visibly more intense, while intensity of the bands corresponding to one or two internal disulfides per protein molecule weakened relative to the no-inositol control. (Full gels are shown in Figure 6supplement 1.) The samples for PEGylation were taken from the bulk solution without mixing, so any aggregates large enough to settle to the bottom of the reaction well were not collected. We have previously shown that W42Q aggregation requires a non-native disulfide in each protein molecule, so the aggregates do not contain any fully reduced protein $;^{7}$ the lower intensities of quadruply-PEGylated bands without inositol in Figure 6B are attributable to lower amounts of the protein remaining soluble at the endpoint of the assay. Thus, surprisingly, myo-inositol was able to shift the molecular population in bulk solution toward the reduced state, despite not being itself redox-active. We therefore propose a mode of action for inositol schematized in Figure 6C: inhibition of the rate-limiting bimolecular step effectively drives the early-stage aggregation process in reverse when a redox buffer is present. We note that HyD itself has some capacity to serve as a redox buffer. ${ }^{7}$

We have previously shown that the concentration-dependence of $W 42 Q$ aggregation rate is quadratic, indicating a bimolecular rate-limiting step. ${ }^{15,23}$ The proposed model in Figure 6C predicts that, by inhibiting this rate-limiting step, myo-inositol could alter the concentration dependence of W42Q aggregation in two ways. First, if it makes a dimer less likely to contribute to aggregation, then it should decrease the pre-exponential factor. Second, if it requires an assembly larger than a dimer to initiate or propagate an aggregate (e.g., a trimer is now required to attain the requisite stability), then it should increase the exponent of the concentration dependence power law. We observed both these effects in the [W42Q]-dependence experiment in Figure 6D.

At the lowest [W42Q], both with and without inositol, the solution turbidity traces became biphasic (Figure 6-supplement 2), as they did at the lowest OxD values with inositol (Figure 5B), while the triple-mutant showed biphasic aggregation throughout (Figure 6A). While a thorough investigation of that behavior is beyond the 
scope of the current study, the most likely hypothesis is that early-stage aggregation is dominated by formation and growth of the aggregates, while later stage (second phase) aggregation is dominated by coalescence of the smaller aggregate particles to form larger ones, as schematized in Figure $\mathbf{3 H}$. The second phase appeared to be more modest for W42Q/C108S/C110S than for W42Q (compare Figure 6A OxD' 0.2 vs. Figure 5B OxD 0.2 and Figure 6-supplement2), perhaps because in addition to non-covalent coalescence, the latter may form disulfides between the solvent-exposed C-terminal Cys residues of subunits from different aggregate particles.
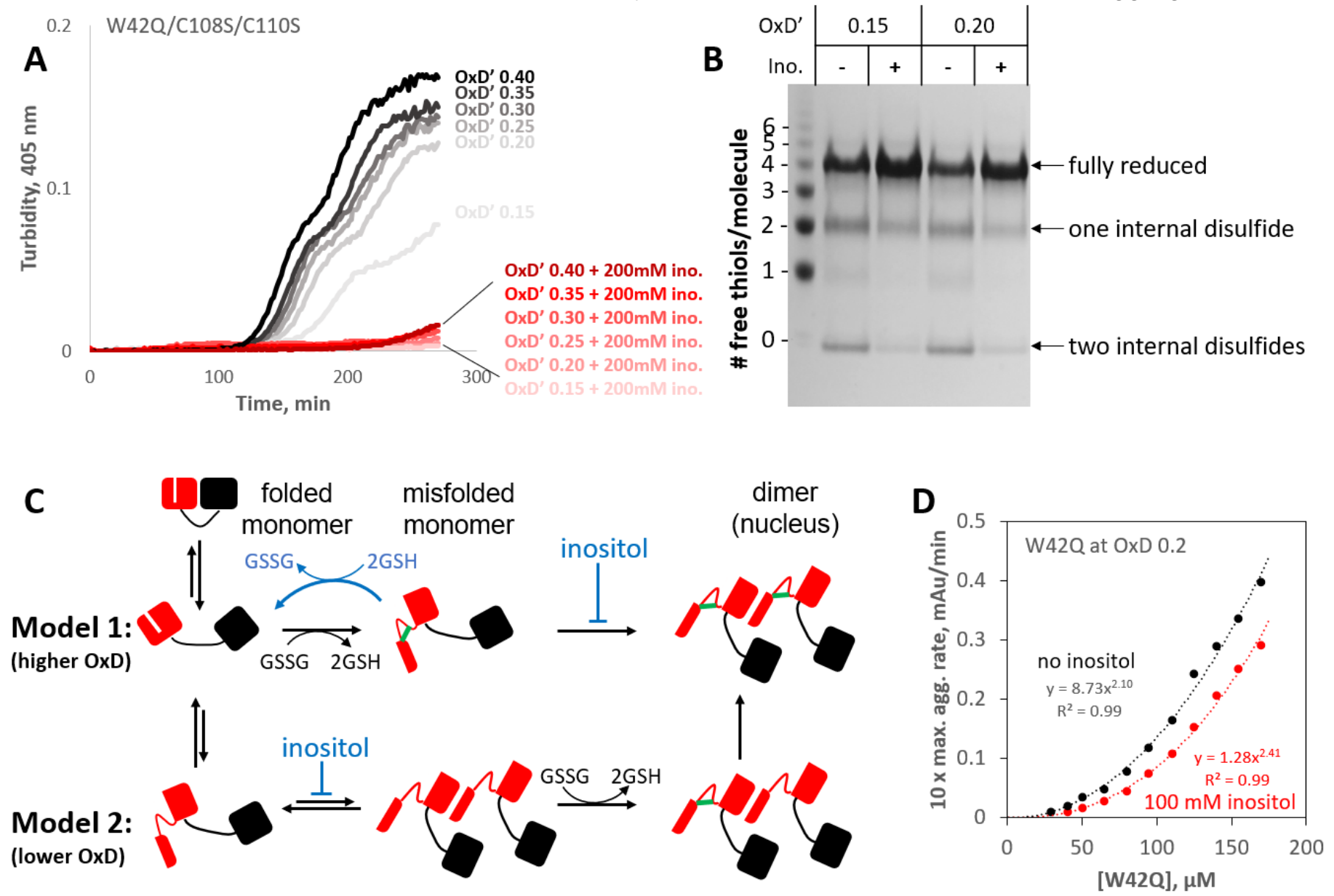

Figure 6: Myo-inositol targets the rate-limiting bimolecular interaction and indirectly favors reduction of disulfide-locked misfolded aggregation precursors. (A) Aggregation of the W42Q/C108S/C110S triple-mutant (lacking the redox-active site in the C-terminal domain) was almost completely suppressed by $200 \mathrm{mM}$ myo-inositol. Here $([G S H]+2[G S S G])$ was only $0.5 \mathrm{mM}$ to facilitate subsequent reaction of the protein with PEG-maleimide; as such, the redox buffers are designated OxD' to distinguish them from those in Figure 5. (B) PEGylation gel-shift assays of the endpoints of aggregation reactions in panel $A$ reveal the redox state distributions of the protein, where 4 free thiols per molecule indicate it is fully reduced; 2 free thiols indicate one internal disulfide; and 0 free thiols, 2 internal disulfides. Markers were generated by limited PEGylation of the WT protein, which contains 6 thiols. The differential effect of inositol was maximal at OxD' 0.15 and 0.2 ; results for higher and lower OxD' values are shown in the figure supplement. (C) Two alternative graphical models explaining how myo-inositol, despite being redox-inert, can alter the redox state distribution indirectly in redox-buffered solutions. Models 1 and 2 are not mutually exclusive and differ from each other by the order of misfolding and oxidation: high and low OxD is expected to favor Model 1 and Model 2, respectively. When disulfide bonding is reversible, inositol may favor reduction and refolding by suppressing the transition from misfolded monomer to transient dimer. (D) Concentration dependence of $\mathrm{W} 42 \mathrm{Q}$ aggregation at OxD 0.2 with and without $100 \mathrm{mM}$ myoinositol. The rightward shift in the curve with inositol (smaller pre-exponential factor) suggests that inositol makes it less likely that a bimolecular interaction will be productive for aggregation, while the larger exponent in the power law further indicates that in the presence of inositol assembly beyond the dimer makes a greater relative contribution to aggregation.

Our observation that myo-inositol primarily targets the early, bimolecular step on the aggregation pathway raises the question of whether it can have an effect when added later in the process, after the initial aggregates have formed. This question has important implications for whether inositol could potentially serve as a treatment for cataract or only as a prophylactic. The model in Figure $6 \mathrm{C}$ predicts that inositol should inhibit the growth of aggregates even when it is added at a later stage because dimerization is important for generating or stabilizing 
the misfolded conformer that is required for continued aggregation. (In the extreme case, aggregate growth at later stages may even proceed via dimer rather than monomer addition.) We therefore carried out experiments in which $\mathrm{W} 42 \mathrm{Q}$ was allowed to aggregate initially at OxD 0.2 as in Figure 5A, followed by addition of inositol after the rapid phase of the aggregation (Figure 7). The initial aggregation was somewhat more rapid than the comparable traces in Figure 5A and Figure 6-supplement 2, respectively, perhaps due to the greater surface area:volume ratio of the initial aggregation reactions; interfaces, including the air-water interface, are known to promote protein misfolding. Nonetheless, when myo-inositol was added to the already-turbid solutions, the rate of further turbidity development became substantially and reproducibly slower than the blank-buffer controls. Thus, myo-inositol can still serve as an aggregation suppressor even at a later stage.

We also carried out a set of experiments with an alternative protocol, in which [W42Q] was kept sufficiently low to generate biphasic aggregation and inositol (or blank buffer) was added during the first phase of the aggregation process, along with enough fresh W42Q to keep [W42Q] constant (Figure 7-supplement 1). In these experiments, mixing produced a significant drop in turbidity, consistent with our prior findings that very-early stage aggregates are fragile. ${ }^{15}$ In all cases, myo-inositol prolonged the first (slow) aggregation phase, consistent with our model that its primary effect is on the dimer and (thereby) on precursor availability. Curves in this experiment became reproducibly multiphasic, pointing to a complex interplay among growth of pre-existing aggregates, formation of new ones from pre-existing precursors, and eventual misfolding of newly added W42Q.

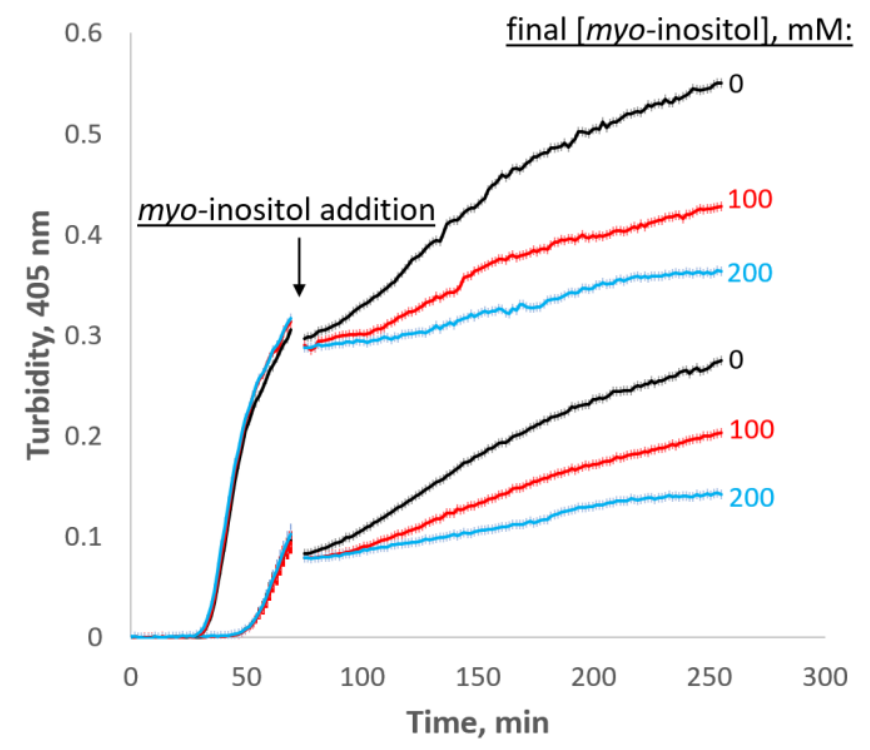

Figure 7: Myo-inositol inhibits aggregation even at later stages. When added late in the aggregation process, myoinositol slowed down the rate of subsequent aggregation in a dose-dependent manner. Triplicate $\mathrm{W} 42 \mathrm{Q}$ samples were allowed to aggregate initially in $60 \mu \mathrm{l}$ volume, then $40 \mu \mathrm{l}$ of myo-inositol solutions or blank buffer was added and the incubation resumed. Light scattering did not change greatly on dilution due to the vertical optics of the plate reader. The discontinuity in the curves shows the dead time of myo-inositol addition and mixing. The curves shown are averages of four technical replicates at each of two different [W42Q] (upper curve, $75 \mu \mathrm{M}$; lower curve, $50 \mu \mathrm{M}$ ) in OxD 0.2 buffer, with error bars showing S.E.M. for each turbidity reading (every $90 \mathrm{~s}$ ).

\section{Discussion}

Natural chemical chaperones, including myo-inositol, are typically expected to stabilize the native state of a protein, either directly by binding it or indirectly by destabilizing the unfolded state. ${ }^{46-48,55-60}$ In some cases, osmolytes have been found to alter aggregate morphology. ${ }^{61,62}$ Inhibitors of aggregation kinetics whose primary target is transient oligomeric states or nuclei have been more challenging to find, let alone characterize, but they are of especially high interest as possible treatments for proteinopathies. ${ }^{63-66}$

Given the strong evolutionary pressure to preserve clear vision, metabolites serving the chemical chaperone function should be expected in eye lenses across much of the animal kingdom. Thus, while human lenses are rich in myo-inositol, rat lenses have less myo-inositol but much more taurine, another potential chemical chaperone. ${ }^{67,68}$ Fish lenses are relatively low in both myo-inositol and taurine but highly enriched in $\mathrm{N}$ acetyl histidine instead. ${ }^{69,70}$ Pharmacological treatment of cataract disease is particularly challenging because the vast majority of even small compounds fail to permeate into this dense and diffusion-limited tissue. ${ }^{32} \mathrm{Natural}$ aggregation-suppressing metabolites could thus be a useful strategy. Myo-inositol, which readily enters the lens thanks to dedicated transporters, ${ }^{41,42}$ had previously been thought of as an osmotic regulator in the lens. ${ }^{71}$ We have now demonstrated that this compound, in the physiological range of its healthy lenticular concentrations, can suppress $\mathrm{y}$-crystallin aggregation and investigated its mode of action. 
bioRxiv preprint doi: https://doi.org/10.1101/2020.12.16.423154; this version posted January $9,2022$. The copyright holder for this preprint (which was not certified by peer review) is the author/funder, who has granted bioRxiv a license to display the preprint in perpetuity. It is made available under aCC-BY-NC 4.0 International license.

We have shown that myo-inositol is a kinetic inhibitor of human yD-crystallin aggregation. It has no observable binding site on the native structure (Figure 2A,B) and only a very minor effect on protein stability (Figure 2C,D) or on the morphology of mature aggregates (Figure 4). Yet, we found evidence that it suppresses an aggregation precursor or early aggregate (Figure 2G,H) and preferentially depletes small aggregates (Figure 4A,D). Further investigation in redox buffers pointed to disruption of the rate-limiting bimolecular interaction that initiates aggregation (Figure 6D). Disfavoring the bimolecular interaction is expected to indirectly favor reduction and refolding of the misfolded monomeric aggregation precursor that is kinetically trapped by non-native disulfide bonding - and this is what we observed (Figure 6B,C). While inositol was an effective aggregation suppressor even in fully oxidizing buffer (Figure 1), it synergized with the glutathione redox couple to suppress aggregation more strongly under mild-to-intermediate levels of oxidation (Figure 5 and Figure 6A). This suggests especially effective kinetic inhibition of the earliest steps on the aggregation pathway of $y$-crystallins during middle age, when the lens fiber cells' cytoplasm is only mildly oxidizing, to delay and slow the development of lens turbidity.

We refer to the proposed target of inositol as a rate-limiting bimolecular interaction, rather than as a dimeric aggregation nucleus, because we have previously shown that the aggregation process is misfoldinglimited, not nucleation-limited. ${ }^{16}$ (That is, "seeding" the reaction by adding pre-aggregated protein to fresh protein does not make the latter aggregate more rapidly.) Why is the rate-limiting interaction bimolecular, even though the key the non-native disulfide bond that locks the aggregation precursor is intramolecular? We have previously carried out extensive atomistic modeling of the misfolding process, which showed detachment of the $\mathrm{N}$-terminal $\beta$-hairpin from the $W 42 Q$ variant and reannealing to non-native locations. ${ }^{16}$ Yet, the intramolecular disulfide bond most favored for promoting aggregation could only form within the context of a dimer that reconstituted the topologically rearranged monomer in a manner akin to domain swapping. ${ }^{16}$ (The Cys-Cys distance was too large in the monomer.) Thus, a dimeric interaction may be the catalyst for non-native disulfide bonding, especially in redox buffers, as indicated in Model 2 of Figure 6C. Inositol may affect the bimolecular interaction in one of three ways: (1) inhibit formation of a dimer; (2) promote dissociation of the dimer; or (3) inhibit a key misfolding event that takes place within the context of the dimer. Determining which of these mechanisms predominates will likely require observing the key dimeric interaction more directly than we are currently able to. In all three cases, however, inositol lowers the concentration of dimer that is productive for the aggregation process, and thereby either disfavors formation or favors reduction of the non-native intramolecular disulfide bonds (Figure 6B).

Another apparent paradox is seen in Figure 7: If inositol inhibits only the early stages of aggregation (i.e., the bimolecular interaction), why is it effective as an aggregation suppressor even after most of the turbidity has already developed? We have previously observed that mature coalesced aggregates settle to the bottom of the reaction vessel during the course of the experiment ${ }^{14,15}$ - an effect that also occurred in the current study but did not significantly affect turbidity measurements due to the vertically oriented optics. We hypothesize that globular aggregate particles coalesce and settle to the bottom of the plate or cuvette and largely cease growing thereafter. Then, continued rise in turbidity depends on continued formation and coalescence of new aggregate particles even as the soluble monomer is gradually depleted. Thus, the microscopic rate-limiting bimolecular interaction determines the number of particles that can finally precipitate as large light-scattering globules. This is consistent with Figure 4D,F, where the number of aggregate particles decreases in $100 \mathrm{mM}$ inositol even though the size of the larger particles does not. The combination of misfolding-limited aggregation kinetics and precipitation of coalesced particles explains why inositol can still inhibit further turbidity development even in already-turbid solutions. If this mechanism translates to the lens, myo-inositol could be used to slow down cataract progression.

Additional research is needed to determine whether myo-inositol suppresses aggregation of other lens crystallins to a comparable degree and whether other compounds based on the inositol scaffold are even better aggregation suppressors. For example, since redox chemistry plays a large role in $\beta \gamma$-crystallin aggregation, ${ }^{7,16}$ and glutathione fails to diffuse into the aging lens, ${ }^{72}$ replacing one hydroxyl of myo-inositol with a thiol might yield a bifunctional anti-cataract drug - an aggregation suppressor and a reducing agent. The inositol transporters expressed in the lens are quite selective, yet one of them (SMIT1) has been shown to import inositols modified with chlorine, fluorine, or azide in at least one position. ${ }^{73}$ Free inositol concentrations and inositol transport capacity need to be measured in healthy lenses across the human lifespan, as existing datasets have focused on aged cataractous lenses for the former and young lenses for the latter. The observation that young lenses have a lower free water content ${ }^{43}$ suggests that effective [myo-inositol] is highest in young age. 
bioRxiv preprint doi: https://doi org/10.1101/2020.12 16.423154; this version posted January 9,2022 . The copyright holder for this preprint (which was not certified by peer review) is the author/funder, who has granted bioRxiv a license to display the preprint in perpetuity. It is made available under aCC-BY-NC 4.0 International license.

A typical human diet is estimated to contain $1-2 \mathrm{~g}$ of myo-inositol per day, and $\sim 4 \mathrm{~g} /$ day is produced endogenously from glucose in the liver and kidney. ${ }^{74}$ Of all human tissues in which myo-inositol levels have been studied, the lens appears to have the highest, while the second-highest levels are found in the cytoplasm of neurons in the brain. ${ }^{74}$ High brain inositol has been ascribed to the need for signaling processes via secondmessenger cascades ${ }^{74}$ but it may also act as a chemical chaperone there. Thus, both myo- and scyllo-inositol, as well as some derivatives, have been shown to directly bind and stabilize oligomers of $A \beta_{42}$, inhibiting amyloid aggregation. ${ }^{75,76}$ Scyllo-inositol has been clinically studied in Alzheimer's disease in humans, with some promise as a disease-modifying agent. ${ }^{77}$ Our finding of myo-inositol's likely aggregation-suppression role in the lens calls for more detailed investigation of whether such activity is general for $\beta$-sheet rich proteins.

Several animal and human studies have observed a relationship between myo-inositol levels and cataract. Thus, in rats with streptozotocin- or galactose-induced cataracts, dietary supplementation with myoinositol dramatically decreased the rate of cataract development: by 14 weeks of age, the untreated animals had totally opaque lenses, while the treated showed only initial stages of cataractogenesis. ${ }^{78}$ In another study, dietary supplementation with myo-inositol triphosphate delayed cataract onset by $\sim 44 \%$ in streptozotocin-induced diabetic rats. ${ }^{79}$ The premise of the rat studies was that myo-inositol might act as an inhibitor of aldose reductase in the lens, but this was found not to be the case. ${ }^{78}$ Direct inhibition of protein aggregation was not considered at the time. Dosage of myo-inositol is likely to be important in any potential cataract treatments, as genetic overexpression of its native lens transporter in mice resulted in cataract due to hyperosmotic stress. ${ }^{80}$ Trisomy21 (Down's syndrome), which leads to overexpression of the same transporter in humans, is likewise associated with premature cataract. ${ }^{81}$ Given that myo-inositol is severely depleted in cataractous human lenses but not in age-matched controls, ${ }^{39,40}$ and given that it is one of the very few molecules able to permeate into lens tissue, maintaining or restoring healthy levels of lens myo-inositol should be considered a promising strategy for delaying the onset of visual impairment or blindness due to cataract and thus reducing the global burden of this highly prevalent disease.

\section{Materials and Methods}

\section{Protein expression and purification}

Wild-type and mutant human $\mathrm{YD}$ crystallin, without any tags, was overexpressed in BL21 RIL E. coli from a pET16b plasmid in SuperBroth medium (Teknova, Hollister, CA) and purified by ammonium sulfate fractionation, ion exchange, and size exclusion as described previously. ${ }^{7}$ For HSQC NMR, ${ }^{15} \mathrm{~N}$-labeled proteins were produced by culturing the cells as above, then centrifuging and resuspending in M9 minimal medium containing $2 \mathrm{~g} / \mathrm{L}$ unlabeled glucose and $1 \mathrm{~g} / \mathrm{L}{ }^{15} \mathrm{~N}$-labeled ammonium acetate (Cambridge Isotope Labs, Tewksbury, MA) and induced with $1 \mathrm{mM}$ IPTG. Due to leaky expression prior to the shift to labeled medium, this expression method resulted in abundant but partially labeled samples. Intact protein electrospray ionization MS showed $\sim 60 \%{ }^{15} \mathrm{~N}$ labelling in $\sim 20 \%$ of the WT sample and $\sim 70 \%{ }^{15} \mathrm{~N}$ labelling in $\sim 60 \%$ of the W42Q sample, with the balance entirely unlabeled. Concentrations for NMR experiments were chosen accordingly to obtain sufficient signal.

\section{Aggregation assays (turbidimetry)}

Aggregation was induced by heating at $37^{\circ} \mathrm{C}$ (unless otherwise indicated) in the presence of either $0.5 \mathrm{mM}$ oxidized glutathione as described previously ${ }^{7}$ or of redox buffer composed of reduced and oxidized glutathione. ${ }^{16}$ Good's buffers were added to a final $10 \mathrm{mM}$ concentration to set sample $\mathrm{pH}$ to a desired level: MES for $\mathrm{pH}$ 6.0, PIPES for $\mathrm{pH}$ 6.7, and HEPES for $\mathrm{pH} 7.4$, with $150 \mathrm{mM} \mathrm{NaCl}$ in all cases. Experiments in the main text were conducted in PIPES pH 6.7 buffer, unless otherwise indicated, because intralenticular pH is known to be slightly below neutral. ${ }^{82} 1 \mathrm{mM}$ EDTA was added to all aggregation reactions to scavenge any trace metals, since some transition metals can promote $\mathrm{HyD}$ aggregation. ${ }^{83}$ All compounds tested as aggregation inhibitors were of high purity. Myo-inositol (>99\%), scyllo-inositol (>98\%), glucose (>99\%), sucrose $(>99.5 \%)$, trehalose $(>99 \%)$, and rhamnose (>99\%) were purchased from MilliporeSigma (Burlington, MA). Galactose (98\%) and arabinose $(99 \%)$ were from Alfa Aesar (Heysham, UK); mannitol (99\%) from BeanTown Chemical (Hudson, NH); glycerol (99.7\%) from Avantor (Radnor, PA); and IPTG (99\%) from Omega Scientific (Tarzana, CA). 
bioRxiv preprint doi: https://doi.org/10.1101/2020.12.16.423154: this version posted January 9 2022. The copyright holder for this preprint (which was not certified by peer review) is the author/funder, who has granted bioRxiv a license to display the preprint in perpetuity. It is made available under aCC-BY-NC 4.0 International license.

To extract the maximum aggregation rate, linear tangents were fitted empirically to the turbidity traces, ${ }^{23}$ and the slope of the best-fit tangent to the steepest part of each curve was used as the maximum rate of aggregation. The $\mathrm{x}$-intercept of that tangent was defined as the apparent lag time (see Figure 6—supplement 2). ${ }^{23,84}$

\section{Solution rheometry}

To test whether $100 \mathrm{mM}$ compounds (as in Figure 1B) affect bulk solution properties, we carried out rheometry using the Discovery HR20 instrument (Waters). Viscosity vs. shear rate was measured by flow sweep for buffer with or without select small carbohydrates at $100 \mathrm{mM}$ concentration at $25^{\circ} \mathrm{C}$ with temperature control on a 40 $\mathrm{mm}$ Peltier plate (parallel) with solvent trap. As positive control (to observe increase in viscosity) we used $20 \%$ glucose. Samples were loaded $(1300 \mu \mathrm{l})$ with $2000 \mu \mathrm{m}$ loading gap with rotations maintained at $1 \mathrm{rad} / \mathrm{s}$ to ensure proper distribution of the fluid/solution on the plate. Measurements were made with $1000 \mu \mathrm{m}$ geometric gap with a prior trim gap offset of $50 \mu \mathrm{m}$. The expansion co-efficient was recorded as $0.0 \mu \mathrm{m} /{ }^{\circ} \mathrm{C}$ with a friction of 0.301432 $\mu \mathrm{N} \cdot \mathrm{m} /(\mathrm{rad} / \mathrm{s})$ and geometric inertia of $8.86649 \mu \mathrm{N} \cdot \mathrm{m} \cdot \mathrm{s}^{2}$. The controlled axial force was maintained at $5.00000 \mathrm{~N}$ with flow torque limit of $0.0100000 \mu \mathrm{N} \cdot \mathrm{m}$, velocity limit of $1.00000 \mu \mathrm{rad} / \mathrm{s}$ and flow velocity tolerance of $5.00 \%$.

\section{NMR data collection and analysis}

NMR experiments were performed on a Bruker Avance II 600-MHz spectrometer equipped with a cryoprobe. HyD WT and W42Q samples were diluted to $45 \mathrm{uM}$ and $30 \mathrm{uM}{ }^{15} \mathrm{~N}$-labelled protein, respectively, in PBS pH 7, $0.1 \mathrm{mM}$ EDTA, $10 \%$ D2O, with or without $100 \mathrm{mM}$ myo-inositol. DTT (2 mM) was added to YD W42Q to prevent aggregation. HSQC spectra were collected at $310 \mathrm{~K}$. Spectra were processed using NMRPipe and data analysis was performed with NMRViewJ.

\section{Differential scanning fluorometry}

Samples were buffer exchanged into $10 \mathrm{mM}$ PIPES pH 6.7 buffer with no added salt (estimated $15 \mathrm{mM}^{\mathrm{N}} \mathrm{Na}^{+}$] final) by gel filtration and used at $40 \mu \mathrm{M}$ for the thermal melts. Lack of salt was found empirically to minimize aggregation. A reducing agent (1 $\mathrm{mM}$ tricarboxyethyl phosphine (TCEP)) was added to prevent oxidative misfolding. 1X SYPRO Orange (Thermo Fisher) was added as the hydrophobicity probe. Melts were carried out using Bio-Rad CFX 96 Touch thermocyclers, with temperature ramping of $1^{\circ} \mathrm{C}$ per minute between 25 and 95 ${ }^{\circ} \mathrm{C}$. Samples were prepared by mixing a $2 \mathrm{X}$ protein sample with the appropriate ratio of aqueous myo-inositol and water and a constant amount of PIPES buffer to avoid any variation in pH or salinity among samples.

\section{Transmission Electron Microscopy}

Samples were prepared in $10 \mathrm{mM}$ PIPES pH 6.7 with $150 \mathrm{mM} \mathrm{NaCl}$ with $1 \mathrm{mM}$ EDTA and $0.5 \mathrm{mM}$ oxidized glutathione (except the control sample, which lacked glutathione) and incubated at $37^{\circ} \mathrm{C}$ in the presence or absence of myo-inositol as indicated for $4 \mathrm{~h}$. They were then kept at room temperature for $\sim 2 \mathrm{~h}$ before being applied to carbon-coated 200-hex copper grids (EMS, Hatfield PA). Freshly ionized grids were floated on a 10 ul drop of sample for 1 minute, then washed with 5 drops of $2 \%$ acidic uranyl acetate, and excess uranyl acetate was drawn off with grade 50 Whatman filter paper. Grids were allowed to dry and imaged with a Hitachi 7800 at $100 \mathrm{KV}$. For maximal precision, aggregate classification and morphometric measurements were carried out manually using contour and area tracing in ImageJ on a stylus-equipped touchscreen. To minimize human bias during this morphometric analysis, a double-blind was implemented as described in Results.

\section{Therman Scanning Raman Spectroscopy}

Raman spectroscopy as a vibrational spectroscopy technique provides a host of structural information and has been a popular choice for spectroscopy of proteins. It is non-destructive, very sensitive to secondary structure, and (unlike FT-IR) largely devoid of water in the crucial Amide I band of the Raman spectrum, where distinct secondary structures have distinct signatures. ${ }^{85-87}$ Additional information rich components like Tryptophan Fermi doublets and phenylalanine pockets make Raman a useful technique in probing tertiary structure, as well. ${ }^{88}$ However, thermal scanning with in-solution proteins is a challenging task not typically attempted with Raman due to sample evaporation and lack of precise temperature control. Thus, we developed a novel apparatus to serve as a thermal scanning Raman spectrometer, as described below. 
Raman spectroscopy was carried out using a Horiba XploRa confocal Raman microscope, a detector thermoelectrically cooled to $-70 \mathrm{C}$, and a $1200 \mathrm{gr} / \mathrm{mm}$ grating blazed at 750 $\mathrm{nm}$. A solid-state $785 \mathrm{~nm}$ laser was used for excitation, with an acquisition time of 180 seconds for all measurements and $1 \mathrm{~cm}^{-1}$ spectral resolution. Typical power levels at the sample were $\sim 41 \mathrm{~mW}$. To allow for automatic removal of cosmic rays, two back-toback spectra were collected. The Horiba denoise algorithm in standard mode was used to slightly smooth the spectra. The fluorescent baseline was fit and subtracted using a polynomial fit. As the excitation wavelength was distant from any protein absorption bands, photo-bleaching or heat induced sample deterioration was not expected. The spectrometer slit was set to $200 \mu \mathrm{m}$. The confocal aperture was set to $500 \mu \mathrm{m}$. The system was calibrated to the $520.7 \mathrm{~cm}^{-1}$ silicon reference sample before every set of measurements. $20 \mu \mathrm{M}$ protein in $10 \mathrm{mM}$ PIPES buffer pH 6.7 and $150 \mathrm{mM} \mathrm{NaCl}$ was used for the measurements with a sample volume of 20ul. Samples with inositol had $200 \mathrm{mM}$ inositol. Since the Raman microscope was confocal, the measurements could be made through a sealed PCR tube with no sample handling. The PCR tube was laid on its side on a microscope slide with a slight tilt to keep the protein solution in the bottom of the tube. The Raman microscope was then focused into the middle of the protein solution. For thermal scanning, a temperature stage was constructed by taping a $10 \mathrm{k} \Omega 25 \mathrm{~W}$ resistor (Digikey MP825-10.0K-1\%-ND) with Kapton tape to the microscope slide. A thermocouple was placed between the PCR tube and the resistor to monitor sample temperature. DC voltage was applied to the resistor to heat the sample; by slowly increasing the voltage and monitoring the thermocouple readout, the temperature could be increased in a controlled manner. The PCR tube was secured on top of the resistor with Kapton tape. Kapton tape was essential for the setup to be able to reach $65^{\circ} \mathrm{C}$. (See Figure $2 \mathrm{E}$ for schematic of thermal stage setup.) Thermal scans were done on the same sample heated in steps. Buffer blanks were carefully taken with buffer and buffer + inositol at every temperature with exactly the same setup and procedure; subtracting the matched blanks was critical for quality spectral readout. All spectra were normalized with respect to the sharp peak at $330 \mathrm{~cm}^{-1}$. To ensure the quality of the protein specific signal, we recorded spectra of WT and compared that with PDB $1 \mathrm{HKO} .{ }^{11} \mathrm{~A}$ comparison of the secondary structure contents as retrieved from our Raman Amide I spectra deconvoluted with Labspec 6 software showed comparable contents with $1 \mathrm{HKO}$. We carried out the same quality check for the isolated $\mathrm{N}$-terminal domain and found its structure content similar to the N-terminal domain of the full-length protein in PDB 1HKO (Figure 2-supplement 1).

\section{Free thiol counting}

PEGylation gel shift assays were carried out essentially as described previously. ${ }^{7}$ A stock solution of PEG(5000)maleimide (MilliporeSigma, Burlington, MA) at $100 \mathrm{mM}$ was prepared in pure DMSO. Immediately prior to protein labeling, NuPAGE 4x LDS loading buffer (BioRad), 0.4 M MES buffer pH 5.8,60\% glycerol, water, and the PEGmaleimide stock solution were mixed in the ratio 10:6:6:5:5, respectively. (MES buffer was needed to neutralize the Tris buffer in NuPAGE, thus minimizing non-specific reactions of maleimide; glycerol was needed to ensure labeled samples settled into the gel wells for SDS-PAGE). End-point samples from the glutathione redoxbuffered protein aggregation reactions were added to this mixture in a $1: 4$ ratio and incubated at $50{ }^{\circ} \mathrm{C}$ for $1 \mathrm{~h}$, then used directly for SDS-PAGE. Markers were prepared by limited PEGylation of WT HyD, which contains 6 free Cys residues: two separate incubations were carried out as above but using only 6:1 and 3:1 molar excess of PEG-maleimide to HyD, respectively, then mixed together and frozen immediately after the $50^{\circ} \mathrm{C}$ incubation. 
bioRxiv preprint doi: https://doi.org/10.1101/2020.12.16.423154; this version posted January 9, 2022. The copyright holder for this preprint (which was not certified by peer review) is the author/funder, who has granted bioRxiv a license to display the preprint in perpetuity. It is made available under aCC-BY-NC 4.0 International license.

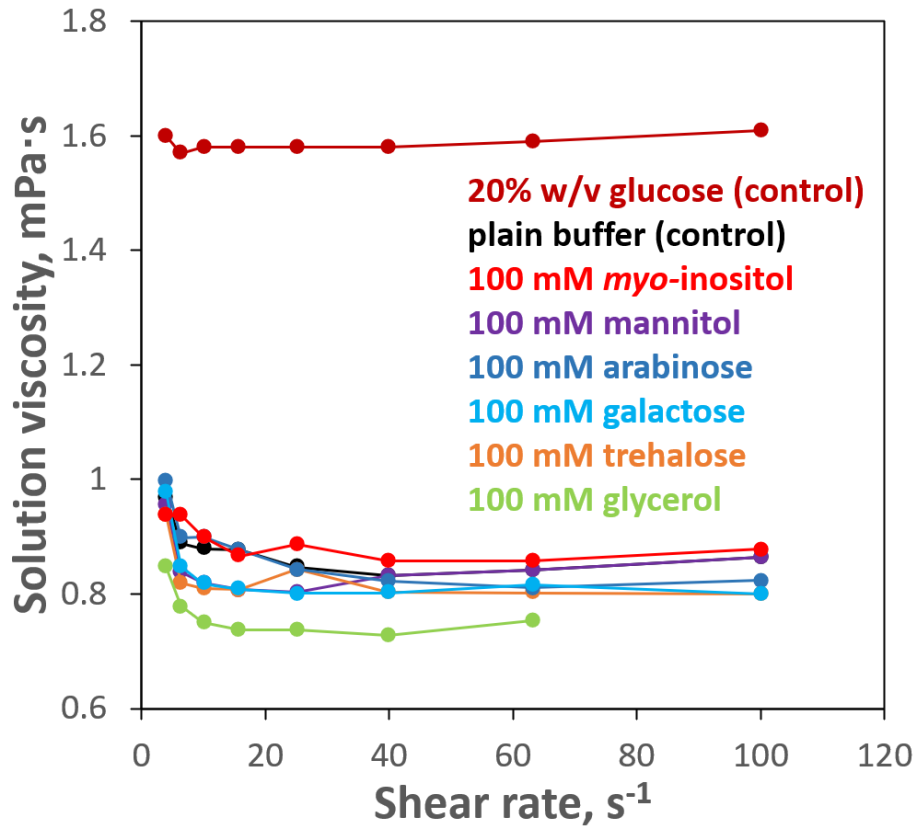

Figure 1 supplement 1: $100 \mathrm{mM}$ inositol does not significantly affect bulk solution properties. Solution rheometry was used to measure viscosity of the aqueous buffer (10 mM PIPES, pH 6.7) with and without 100 mM myo-inositol or select other compounds. No meaningful difference was observed between $100 \mathrm{mM}$ myo-inositol and plain buffer. Changes produced by the other compounds were minor. As a positive control, $20 \% \mathrm{w} / \mathrm{v}$ glucose is shown; this concentration $(\sim 1.1 \mathrm{M})$ is more typical of the range in which stabilizing effects of protective osmolytes are observed.

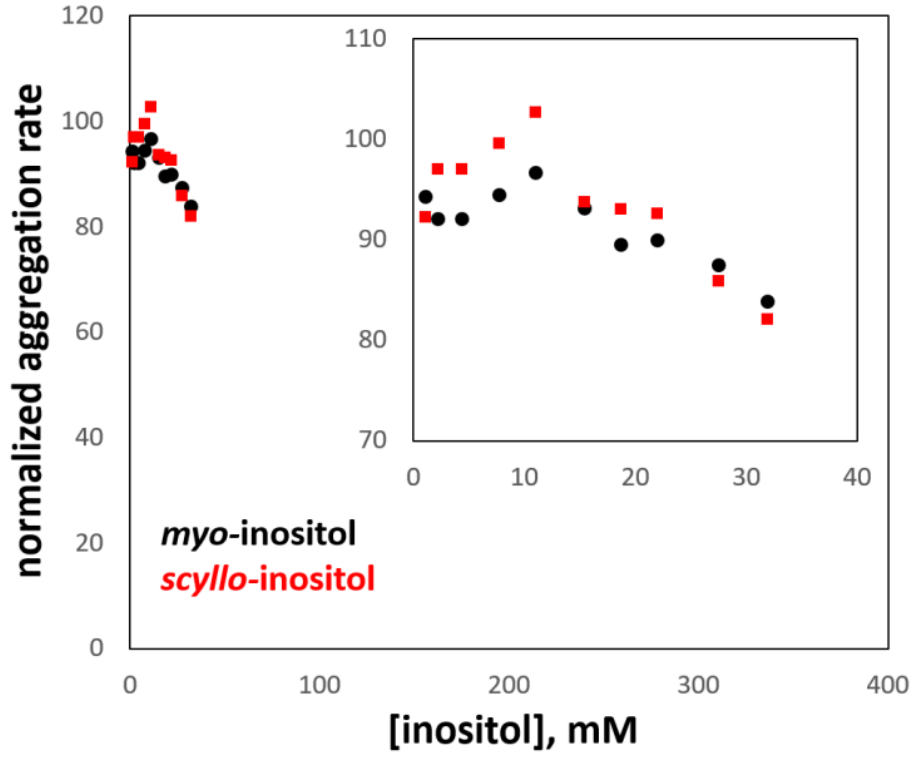

Figure 1 supplement 2: Comparison of myo- and scyllo-inositol. Both compounds were tested in parallel for their ability to suppress aggregation of the W42Q HyD variant, exactly as in Figure 1A. However, scyllo-inositol's solubility is an order of magnitude lower than that of the more common myo- isomer, which strictly constrained the testable concentration range. In this range, no significant difference was observed between myo- and scyllo-inositol. The axes are scaled to match Figure $1 C, D$; the inset shows a zoom-in of the data series. All aggregation rates are expressed as $\%$ of the rate without inositol. 

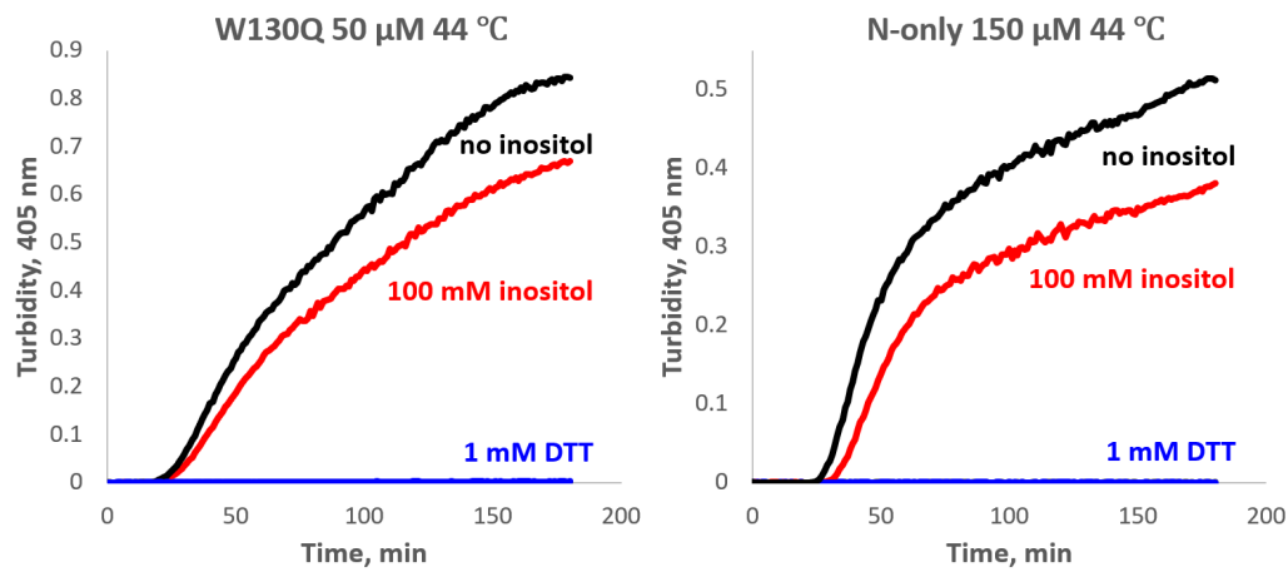

Figure 1 supplement 3: Aggregation of $\mathrm{W} 130 \mathrm{Q}$ and isolated WT N-terminal domain is completely redox-dependent. The proteins were aggregated in $10 \mathrm{mM}$ PIPES pH6.7, $150 \mathrm{mM} \mathrm{NaCl}$ buffer with $0.5 \mathrm{mM}$ GSSG and $1 \mathrm{mM}$ EDTA, at the temperature and concentrations shown, with or without $100 \mathrm{mM}$ myo-inositol. In the control reactions, $0.5 \mathrm{mM}$ GSSG was replaced with $1 \mathrm{mM}$ DTT, resulting in no detectable aggregation (blue traces).

A

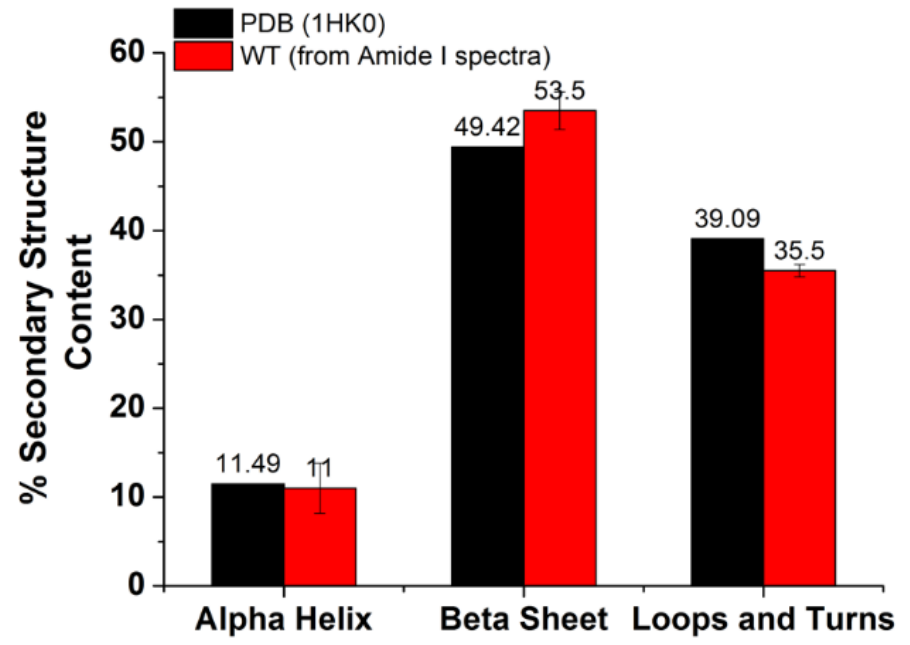

B

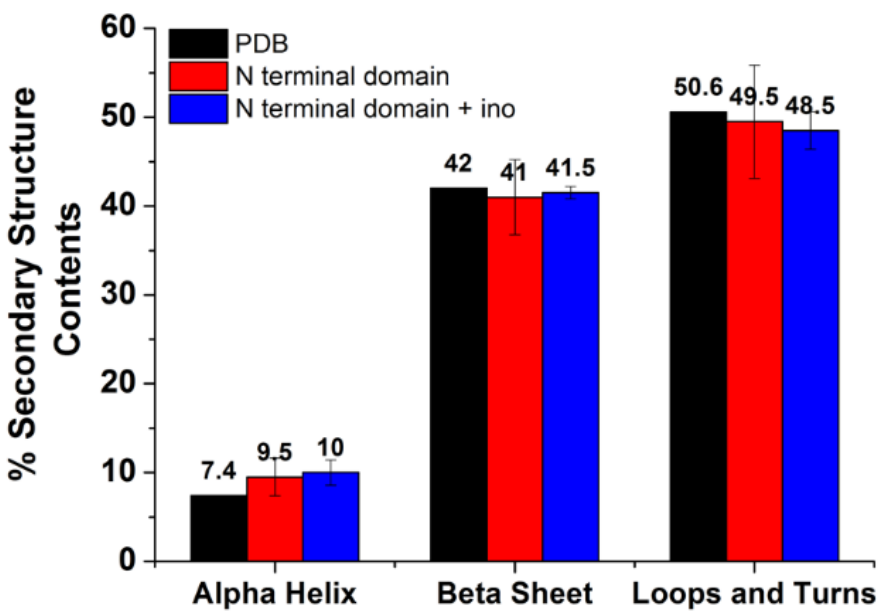

Figure 2 supplement 1: Secondary structure contents of the WT and $\mathbf{N}$ terminal domain obtained upon deconvolution of the Amide I Raman spectra were found to be comparable to the reported crystal structure (1HK0). (A) To check the quality of the Raman Spectra (Amide I range, 1600 to $1700 \mathrm{~cm}^{-1}$ ), we compared the secondary structure content (i.e. \% of alpha helix, beta sheet and loops and turns) of the WT with the reported crystal structure (1HK0). Comparative bar plot shows comparable secondary structure contents. (B) Comparative bar plot for the secondary structure contents shows $\mathrm{N}$-terminal domain secondary structure contents $\left(\right.$ at $\left.25{ }^{\circ} \mathrm{C}\right)$ are comparable with the reported structure (1HK0-truncated $\mathrm{N}$-terminal domain). Furthermore, the $\mathrm{N}$-terminal domain with and without inositol had very similar secondary structure content, showing that inositol had no effect on the native secondary structure of the $\mathrm{N}$-terminal domain (temperature $=25^{\circ} \mathrm{C}$ ). 
bioRxiv preprint doi: https://doi.org/10.1101/2020.12.16.423154; this version posted January 9, 2022. The copyright holder for this preprint (which was not certified by peer review) is the author/funder, who has granted bioRxiv a license to display the preprint in perpetuity. It is made available under aCC-BY-NC 4.0 International license.

\begin{tabular}{|c|c|c|c|c|c|c|}
\hline OxD': & \multicolumn{2}{|c|}{0.05} & \multicolumn{2}{|c|}{0.10} & \multicolumn{2}{|c|}{0.15} \\
\hline Ino.: & - & + & - & + & - & + \\
\hline
\end{tabular}

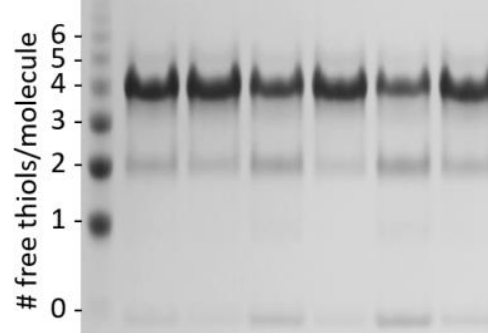

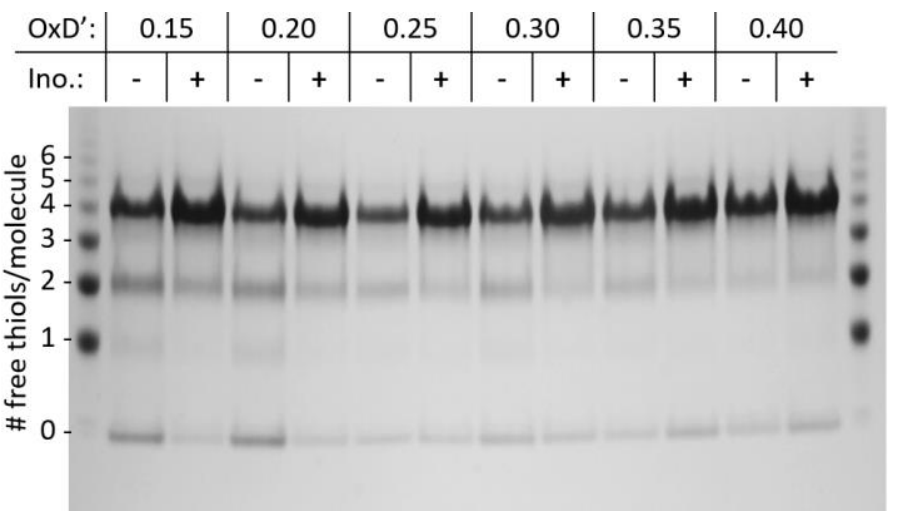

Figure 6 supplement 1: PEGylation gel shift assays reveal shifts in the redox distribution of the W42Q/C108S/C110S protein induced by $200 \mathrm{mM}$ myo-inositol. SDS-PAGE gels from two separate experiments are shown, at the OxD' values indicated. The differences are greatest in the intermediate OxD' range (0.10-0.30). The left marker lane and first 4 sample lanes are what is shown in Figure 6B. At OxD' 0.05, too little aggregation took place for the differences to become clear. Beyond OxD' 0.3, the singly and doubly disulfide-bonded precursors were lost from the inositol-free samples, and the two distributions showed hints of a reversal. The likely explanation is that at high OxD' without inositol, precursors have already aggregated and precipitated by the end-point of the assay at the higher OxD' values, while in the presence of inositol a fraction of doubly-disulfide bonded aggregates is still soluble, along with the fraction that remains fully reduced. It is also worth noting that precipitation of the aggregated protein leads to removal of disulfide bonds from the solution, so the true final OxD' value is lower in the absence of inositol when protein aggregation is sufficiently extensive to lower soluble [GSSG].
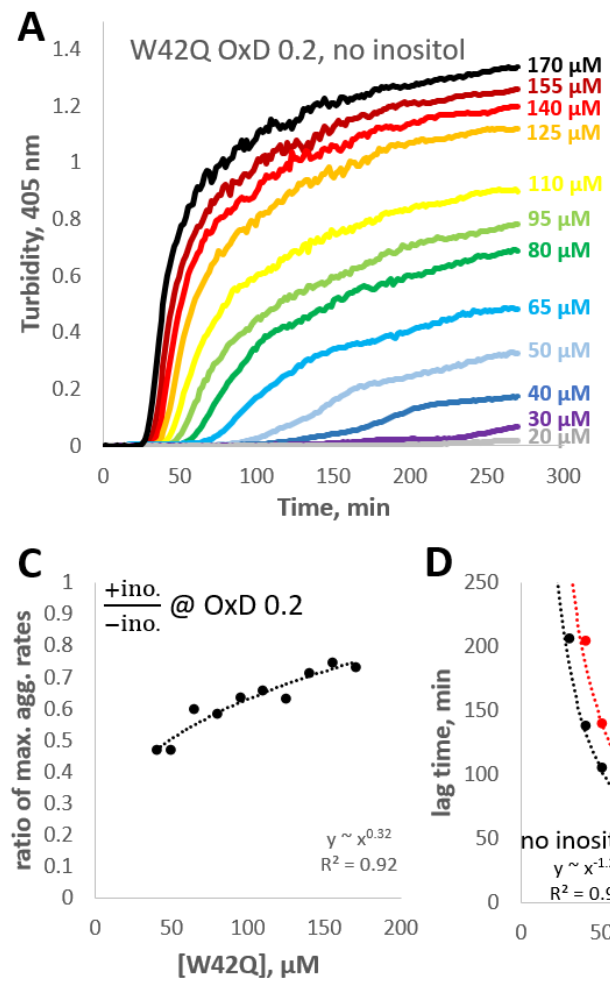

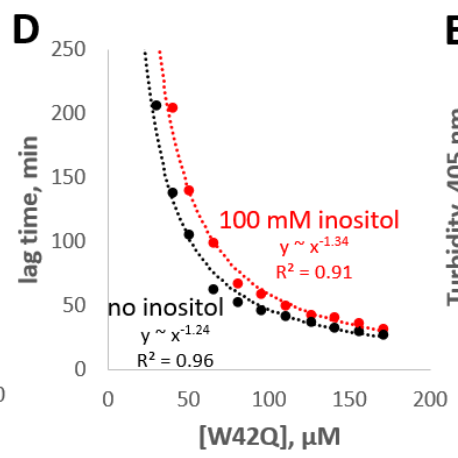

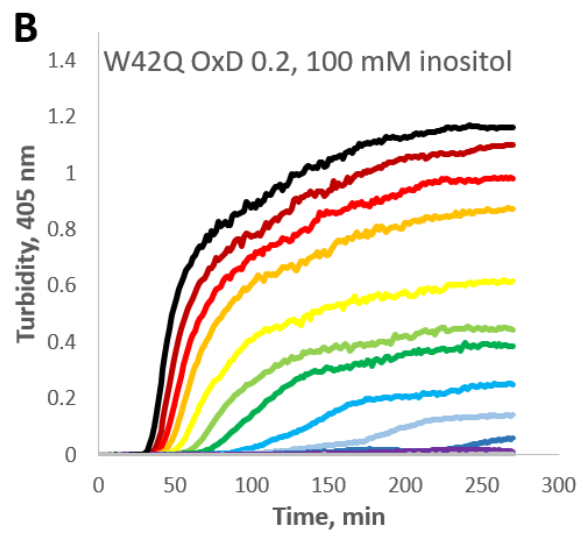

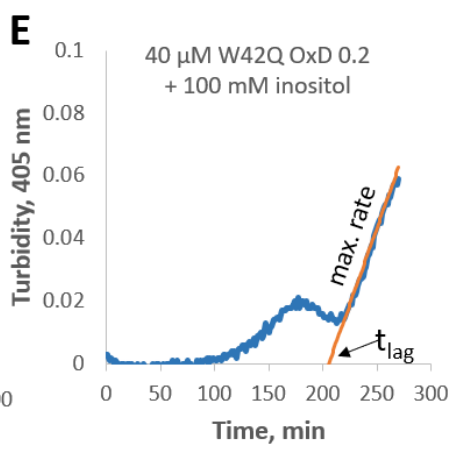

Figure 6 supplement 2: Concentration-dependence of W42Q aggregation curves with and without myo-inositol. $(A, B)$ The full solution turbidity traces, from which maximum rates were extracted for Figure 6D. (C) Ratios of the maximum aggregation rate show dependence on concentration; in other words, inositol was most effective at suppressing aggregation at lower [W42Q], as should be expected from a suppressor of aggregate formation rather than coalescence. (D) Lag times for the curves in panels $A$ and $B$. (E) An illustration of the empirical fitting procedure for extracting the maximum rates and lag times from the solution turbidity curves, on the example of the second-lowest curve in panel B. Note that when the aggregation curves were biphasic the fits were applied only to phase 2, when turbidity rose the most rapidly. This fitting procedure was also the main reason for the large increase in apparent lag times in Figure 5C. 
bioRxiv preprint doi: https://doi org/10.1101/2020.12.16.423154: this version posted January 9 2022. The copyright holder for this preprint (which was not certified by peer review) is the author/funder, who has granted bioRxiv a license to display the preprint in perpetuity. It is made available under aCC-BY-NC 4.0 International license.
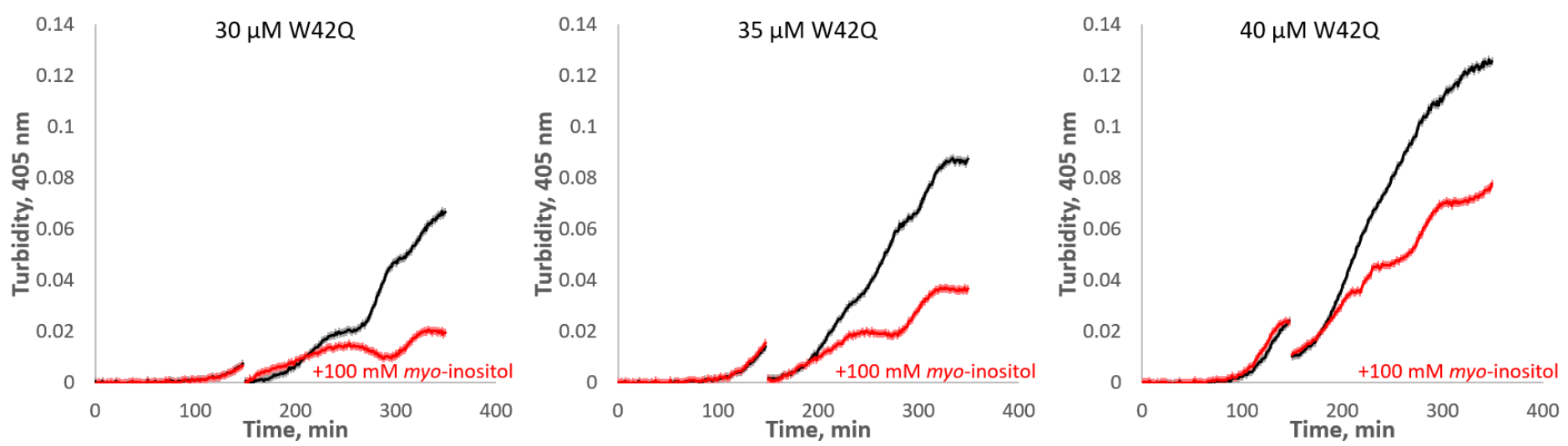

Figure 7 supplement 1: Myo-inositol extends the first (slow) phase of aggregation when added early in the aggregation process. HyD W42Q samples at the indicated concentrations were allowed to begin aggregating in $75 \mu \mathrm{l}$ volume, followed by addition of $25 \mu \mathrm{l}$ buffer or inositol to the final concentration of $100 \mathrm{mM}$ along with sufficient W42Q to maintain total [W42Q] at the indicated value. The discontinuities in the curves are the times of inositol addition and mixing. Four technical replicates were carried out in parallel for each set of curves, and the curves shown consist of averages \pm S.E.M. of the replicates.

Lam, D. et al. Cataract. Nature Reviews Disease Primers 1, 15, doi:10.1038/nrdp.2015.14 (2015). Bloemendal, H. et al. Ageing and vision: structure, stability and function of lens crystallins. Prog Biophys Mol Biol 86, 407-485, doi:10.1016/j.pbiomolbio.2003.11.012 (2004).
Su, S. et al. Proteomic Analysis of Human Age-related Nuclear Cataracts and Normal Lens Nuclei. Invest Ophthalmol Vis Sci 52, 4182-4191, doi:10.1167/iovs.10-7094 (2011). Hains, P. G. \& Truscott, R. J. Post-translational modifications in the nuclear regio
human lenses. J Proteome Res 6, 3935-3943, doi:10.1021/pr070138h (2007). Biophysics \& Molecular Biology 115, 32-41 (2014).

Wride, M. A. Lens fibre cell differentiation and organelle loss: many paths lead to clarity. Philos Trans $R$ Soc Lond B Biol Sci 366, 1219-1233, doi:10.1098/rstb.2010.0324 (2011).

Serebryany, E., Yu, S., Trauger, S. A., Budnik, B. \& Shakhnovich, E. I. Dynamic disulfide exchange in a crystallin protein in the human eye lens promotes cataract-associated aggregation. J. Biol. Chem. 293, 17997-18009, doi:10.1074/jbc.RA118.004551 (2018).

Kosinski-Collins, M. S. \& King, J. In vitro unfolding, refolding, and polymerization of human gamma D crystallin, a protein involved in cataract formation. Protein Sci. 12, 480-490, doi:10.1110/ps.0225503 (2003).

Mills-Henry, I. A., Thol, S. L., Kosinski-Collins, M. S., Serebryany, E. \& King, J. A. Kinetic stability of long-lived human gamma-D and gamma-S crystallins and their isolated double Greek Key domains. Biophys. J. Accepted (2019).

Serebryany, E., Thorn, D. C. \& Quintanar, L. Redox chemistry of lens crystallins: A system of cysteines. Experimental Eye Research 211, doi:10.1016/j.exer.2021.108707 (2021).

Basak, A. et al. High-resolution X-ray crystal structures of human gamma D crystallin (1.25 angstrom) and the R58H mutant (1.15 angstrom) associated with aculeiform cataract. J. Mol. Biol. 328, 1137-1147 (2003).

2 Ramkumar, S., Fan, X., Wang, B., Yang, S. \& Monnier, V. M. Reactive cysteine residues in the oxidative dimerization and Cu2+ induced aggregation of human $\gamma D$-crystallin: Implications for age-related cataract. Biochim Biophys Acta 1864, 3595-3604 (2018).

3 Fan, X. et al. Evidence of Highly Conserved $\beta$-Crystallin Disulfidome that Can be Mimicked by In Vitro Oxidation in Age-related Human Cataract and Glutathione Depleted Mouse Lens. Mol. Cell. Proteomics 14, 3211-3223 (2015).

Serebryany, E. et al. Aggregation of Trp > Glu point mutants of human gamma-D crystallin provides a model for hereditary or UV-induced cataract. Protein Sci. 25, 1115-1128, doi:10.1002/pro.2924 (2016). 
bioRxiv preprint doi: https://doi.org/10.1101/2020.12.16.423154; this version posted January 9, 2022. The copyright holder for this preprint (which was not certified by peer review) is the author/funder, who has granted bioRxiv a license to display the preprint in perpetuity. It is made available under aCC-BY-NC 4.0 International license.

Serebryany, E. \& King, J. A. Wild-type human gammaD-crystallin promotes aggregation of its oxidationmimicking, misfolding-prone W42Q mutant. J. Biol. Chem. 290, 11491-11503, doi:10.1074/jbc.M114.621581 (2015).

Serebryany, E. et al. An Internal Disulfide Locks a Misfolded Aggregation-prone Intermediate in Cataract-linked Mutants of Human YD-Crystallin. J. Biol. Chem. 291, 19172-19183 (2016). Wang, B. B. et al. A Novel CRYGD Mutation (p.Trp43Arg) Causing Autosomal Dominant Congenital Cataract in a Chinese Family. Human Mutation 32, E1939-E1947, doi:10.1002/humu.21386 (2011). Metlapally, S. et al. Analysis of nuclear fiber cell cytoplasmic texture in advanced cataractous lenses from Indian subjects using Debye-Bueche theory. Exp. Eye Res. 86, 434-444, doi:10.1016/j.exer.2007.11.018 (2008). Costello, M. J. et al. Electron tomography of fiber cell cytoplasm and dense cores of multilamellar bodies from human age-related nuclear cataracts. Exp. Eye Res. 101, 72-81, doi:10.1016/j.exer.2012.06.005 (2012). schafheimer, N. \& King, J. Tryptophan cluster protects human gammaD-crystallin from ultraviolet radiationinduced photoaggregation in vitro. Photochem Photobiol 89, 1106-1115, doi:10.1111/php.12096 (2013). Roskamp, K. W. et al. Multiple Aggregation Pathways in Human gamma S-Crystallin and Its Aggregation-Prone G18V Variant. Investigative Ophthalmology \& Visual Science 58, 2397-2405, doi:10.1167/iovs.16-20621 (2017). Moran, S. D., Zhang, T. O., Decatur, S. M. \& Zanni, M. T. Amyloid fiber formation in human gammaD-Crystallin induced by UV-B photodamage. Biochemistry 52, 6169-6181, doi:10.1021/bi4008353 (2013). Serebryany, E., Jacobs, W. M., Razban, R. M. \& Shakhnovich, E. I. Conformational catalysis of cataract-associated aggregation in a human eye lens crystallin occurs via interface stealing. BiorXiv, doi:https://doi.org/10.1101/601708 (2019). Zhao, L. et al. Lanosterol reverses protein aggregation in cataracts. Nature 523, 607-+, doi:10.1038/nature14650 (2015). Shanmugam, P. M. et al. Effect of lanosterol on human cataract nucleus. Indian J. Ophthalmol. 63, 888-890, doi:10.4103/0301-4738.176040 (2015). Makley, L. N. et al. Pharmacological chaperone for alpha-crystallin partially restores transparency in cataract models. Science 350, 674-677, doi:10.1126/science.aac9145 (2015). United States. Archives of Ophthalmology 125, 544-550, doi:10.1001/archopht.125.4.544 (2007). Kara, N., Almeida, H. G., Jorge, P. D., Carricondo, P. C. \& Kara-Jose, N. Consequences of cataract surgery public policies run by private contractors. Arq. Bras. Oftalmol. 80, V-VI, doi:10.5935/0004-2749.20170001 (2017). Organization, W. H. Visual Impairment and Blindness, <http://www.who.int/en/news-room/factsheets/detail/blindness-and-visual-impairment> (2014). Khairallah, M. et al. Number of People Blind or Visually Impaired by Cataract Worldwide and in World Regions, 1990 to 2010. Investigative Ophthalmology \& Visual Science 56, 6762-6769, doi:10.1167/iovs.15-17201 (2015). Wang, W. et al. Cataract Surgical Rate and Socioeconomics: A Global Study. Investigative Ophthalmology \& Visual Science 57, 5872-5881, doi:10.1167/iovs.16-19894 (2016). Heilkkinen, E. M. et al. Distribution of Small Molecular Weight Drugs into the Porcine Lens: Studies on Imaging Mass Spectrometry, Partition Coefficients, and Implications in Ocular Pharmacokinetics. Molecular Pharmaceutics 16, 3968-3976, doi:10.1021/acs.molpharmaceut.9b00585 (2019). Crystallins. Accounts of Chemical Research 53, 863-874, doi:10.1021/acs.accounts.0c00014 (2020). Lampi, K. J., Wilmarth, P. A., Murray, M. R. \& David, L. L. Lens beta-crystallins: the role of deamidation and related modifications in aging and cataract. Prog Biophys Mol Biol 115, 21-31, doi:10.1016/j.pbiomolbio.2014.02.004 (2014). Slingsby, C., Wistow, G. J. \& Clark, A. R. Evolution of crystallins for a role in the vertebrate eye lens. Protein Science 22, 367-+, doi:10.1002/pro.2229 (2013).

36 Goulet, D. R., Knee, K. M. \& King, J. A. Inhibition of unfolding and aggregation of lens protein human gamma D crystallin by sodium citrate. Experimental Eye Research 93, 371-381, doi:10.1016/j.exer.2011.04.011 (2011). Attanasio, F. et al. Trehalose effects on alpha-crystallin aggregates. Biochemical and Biophysical Research Communications 354, 899-905, doi:10.1016/j.bbrc.2007.01.061 (2007). 
bioRxiv preprint doi: https://doi.org/10.1101/2020.12.16.423154; this version posted January 9, 2022. The copyright holder for this preprint (which was not certified by peer review) is the author/funder, who has granted bioRxiv a license to display the preprint in perpetuity. It is made available under aCC-BY-NC 4.0 International license.

39 Tsentalovich, Y. P. et al. Metabolomic composition of normal aged and cataractous human lenses. Experimental Eye Research 134, 15-23, doi:10.1016/j.exer.2015.03.008 (2015).

40 Yanshole, V. V., Yanshole, L. V., Snytnikova, O. A. \& Tsentalovich, Y. P. Quantitative metabolomic analysis of changes in the lens and aqueous humor under development of age-related nuclear cataract. Metabolomics 15, doi:10.1007/s11306-019-1495-4 (2019).

41 Cotlier, E. MYO-INOSITOL - ACTIVE TRANSPORT BY CRYSTALLINE LENS. Investigative Ophthalmology 9, 681-+ (1970).

42 Diecke, F. P. J., Beyermears, A. \& Mistry, K. KINETICS OF MYOINOSITOL TRANSPORT IN RAT OCULAR LENS. Journal of Cellular Physiology 162, 290-297, doi:10.1002/jcp.1041620215 (1995).

43 Heys, K. R., Friedrich, M. G. \& Truscott, R. J. W. Free and bound water in normal and cataractous human lenses. Investigative Ophthalmology \& Visual Science 49, 1991-1997, doi:10.1167/iovs.07-1151 (2008).

44 Flaugh, S. L., Mills-Henry, I. A. \& King, J. Glutamine deamidation destabilizes human gammaD-crystallin and lowers the kinetic barrier to unfolding. J. Biol. Chem. 281, 30782-30793, doi:10.1074/jbc.M603882200 (2006). Mills-Henry, I. A., Flaugh, S. L., Kosinski-Collins, M. S. \& King, J. A. Folding and stability of the isolated Greek key domains of the long-lived human lens proteins gammaD-crystallin and gammaS-crystallin. Protein Sci 16, 24272444, doi:10.1110/ps.072970207 (2007).

46 Street, T. O., Bolen, D. W. \& Rose, G. D. A molecular mechanism for osmolyte-induced protein stability. Proc. Natl. Acad. Sci. U. S. A. 103, 13997-14002, doi:10.1073/pnas.0606236103 (2006).

47 Dandage, R. et al. Classification of Chemical Chaperones Based on Their Effect on Protein Folding Landscapes. Acs Chemical Biology 10, 813-820, doi:10.1021/cb500798y (2015).

48 Okiyoneda, T. et al. Mechanism-based corrector combination restores Delta F508-CFTR folding and function. Nature Chemical Biology 9, 444-U469, doi:10.1038/nchembio.1253 (2013).

49 Williams, R. W. ESTIMATION OF PROTEIN SECONDARY STRUCTURE FROM THE LASER RAMAN AMIDE-I SPECTRUM. Journal of Molecular Biology 166, 581-603, doi:10.1016/s0022-2836(83)80285-x (1983).

50 Williams, R. W. \& Dunker, A. K. DETERMINATION OF THE SECONDARY STRUCTURE OF PROTEINS FROM THE AMIDE-I BAND OF THE LASER RAMAN-SPECTRUM. Journal of Molecular Biology 152, 783-813, doi:10.1016/00222836(81)90127-3 (1981).

51 Ganim, Z. et al. Amide I two-dimensional infrared Spectroscopy of proteins. Accounts of Chemical Research 41, 432-441, doi:10.1021/ar700188n (2008).

52 Holzbaur, I. E., English, A. M. \& Ismail, A. A. FTIR study of the thermal denaturation of horseradish and cytochrome c peroxidases in D2O. Biochemistry 35, 5488-5494, doi:10.1021/bi952233m (1996).

53 Byler, D. M. \& SUSi, H. EXAMINATION OF THE SECONDARY STRUCTURE OF PROTEINS BY DECONVOLVED FTIR SPECTRA. Biopolymers 25, 469-487, doi:10.1002/bip.360250307 (1986).

54 Romero-Aristizabal, C., Marks, D. S., Fontana, W. \& Apfeld, J. Regulated spatial organization and sensitivity of cytosolic protein oxidation in Caenorhabditis elegans. Nat. Commun. 5, doi:10.1038/ncomms6020 (2014). Beg, I., Minton, A. P., Islam, A., Hassan, M. I. \& Ahmad, F. The pH Dependence of Saccharides' Influence on Thermal Denaturation of Two Model Proteins Supports an Excluded Volume Model for Stabilization Generalized to Allow for Intramolecular Electrostatic Interactions. J. Biol. Chem. 292, 505-511, doi:10.1074/jbc.M116.757302 (2017).

56 Gupta, A. N. et al. Pharmacological chaperone reshapes the energy landscape for folding and aggregation of the prion protein. Nat. Commun. 7, doi:10.1038/ncomms12058 (2016).

57 Dong, C. H., Garen, C. R., Mercier, P., Petersen, N. O. \& Woodside, M. T. Characterizing the inhibition of alphasynuclein oligomerization by a pharmacological chaperone that prevents prion formation by the protein $\operatorname{PrP}$. Protein Sci. 28, 1690-1702, doi:10.1002/pro.3684 (2019).

58 Gault, J. et al. Mass Spectrometry Reveals the Direct Action of a Chemical Chaperone. J. Phys. Chem. Lett. 9, 4082-4086, doi:10.1021/acs.jpclett.8b01817 (2018).

59 Clark, N. E., Metcalf, M. C., Best, D., Fleet, G. W. J. \& Garman, S. C. Pharmacological chaperones for human alpha-N-acetylgalactosaminidase. Proc. Natl. Acad. Sci. U. S. A. 109, 17400-17405, doi:10.1073/pnas.1203924109 (2012).

60 Morgan, G. J. et al. Stabilization of amyloidogenic immunoglobulin light chains by small molecules. Proc. Natl. Acad. Sci. U. S. A. 116, 8360-8369, doi:10.1073/pnas.1817567116 (2019).

61 Marasini, C., Vesterga, B. \& Vestergaard, B. Sucrose modulates insulin amyloid-like fibril formation: effect on the aggregation mechanism and fibril morphology. Rsc Advances 7, 10487-10493, doi:10.1039/c6ra25872g (2017). 
bioRxiv preprint doi: https://doi.org/10.1101/2020.12.16.423154; this version posted January 9, 2022. The copyright holder for this preprint

(which was not certified by peer review) is the author/funder, who has granted bioRxiv a license to display the preprint in perpetuity. It is made available under aCC-BY-NC 4.0 International license.

62 Bashir, S. et al. Biophysical Elucidation of Fibrillation Inhibition by Sugar Osmolytes in alpha-Lactalbumin: Multispectroscopic and Molecular Docking Approaches. Acs Omega 5, 26871-26882, doi:10.1021/acsomega.0c04062 (2020). Ignatova, Z. \& Gierasch, L. M. Inhibition of protein aggregation in vitro and in vivo by a natural osmoprotectant. Proc. Natl. Acad. Sci. U. S. A. 103, 13357-13361, doi:10.1073/pnas.0603772103 (2006). Habchi, J. et al. An anticancer drug suppresses the primary nucleation reaction that initiates the production of the toxic A beta 42 aggregates linked with Alzheimer's disease. Science Advances 2, doi:10.1126/sciadv.1501244 (2016). Giorgetti, S., Greco, C., Tortora, P. \& Aprile, F. A. Targeting Amyloid Aggregation: An Overview of Strategies and Mechanisms. International Journal of Molecular Sciences 19, doi:10.3390/ijms19092677 (2018). Petrosyan, R., Patra, S., Rezajooei, N., Garen, C. R. \& Woodside, M. T. Unfolded and intermediate states of PrP play a key role in the mechanism of action of an antiprion chaperone. Proc. Natl. Acad. Sci. U. S. A. 118, doi:10.1073/pnas.2010213118 (2021).

67 Kinoshita, J. H., Barber, G. W., O.Merola, L. \& Tung, B. Changes in the levels of free amino acids and myo-inositol in the galactose-exposed lens. Invest. Ophthalmol. Vis. Sci. 8, 625-632 (1969). Yanshole, V. V. et al. Metabolomics of the rat lens: A combined LC-MS and NMR study. Experimental Eye Research 125, 71-78, doi:10.1016/j.exer.2014.05.016 (2014).

69 Tsentalovich, Y. P. et al. Seasonal Variations and Interspecific Differences in Metabolomes of Freshwater Fish Tissues: Quantitative Metabolomic Profiles of Lenses and Gills. Metabolites 9, doi:10.3390/metabo9110264 (2019).

Rhodes, J. D., Breck, O., Waagbo, R., Bjerkas, E. \& Sanderson, J. N-acetylhistidine, a novel osmolyte in the lens of Atlantic salmon (Salmo salar L.). American Journal of Physiology-Regulatory Integrative and Comparative Physiology 299, R1075-R1081, doi:10.1152/ajpregu.00214.2010 (2010).

71 Zhou, C., Chen, H. Q., Reeves, R., Agarwal, N. \& Cammarata, P. R. OSMOREGULATORY ALTERATIONS IN MYOINOSITOL UPTAKE BY BOVINE LENS EPITHELIAL-CELLS .4. INDUCTION-PATTERN OF NA+-MYO-INOSITOL COTRANSPORTER MESSENGER-RNA UNDER HYPERTONIC CONDITIONS DENOTING AN EARLY-ONSET, INTERACTIVE, PROTECTIVE MECHANISM AGAINST WATER-STRESS. Investigative Ophthalmology \& Visual Science 35, 4118-4125 (1994).

72 Lim, J. C., Grey, A. C., Zahraei, A. \& Donaldson, P. J. Age-dependent changes in glutathione metabolism pathways in the lens: New insights into therapeutic strategies to prevent cataract formation. Clinical \& Experimental Ophthalmology 2020, 1031-1042, doi:10.1111/ceo.13801 (2020).

Fenili, D., Weng, Y. Q., Aubert, I., Nitz, M. \& McLaurin, J. Sodium/myo-Inositol Transporters: Substrate Transport Requirements and Regional Brain Expression in the TgCRND8 Mouse Model of Amyloid Pathology. Plos One 6, doi:10.1371/journal.pone.0024032 (2011).

Fisher, S. K., Novak, J. E. \& Agranoff, B. W. Inositol and higher inositol phosphates in neural tissues: homeostasis, metabolism and functional significance. Journal of Neurochemistry 82, 736-754, doi:10.1046/j.1471-

4159.2002.01041.x (2002).

75 McLaurin, J., Golomb, R., Jurewicz, A., Antel, J. P. \& Fraser, P. E. Inositol stereoisomers stabilize an oligomeric aggregate of Alzheimer amyloid beta peptide and inhibit A beta-induced toxicity. J. Biol. Chem. 275, 1849518502, doi:10.1074/jbc.M906994199 (2000).

76 Sun, Y. D. et al. Synthesis of scyllo-inositol derivatives and their effects on amyloid beta peptide aggregation. Bioorganic \& Medicinal Chemistry 16, 7177-7184, doi:10.1016/j.bmc.2008.06.045 (2008).

77 Tariot, P. et al. The Effects of ELND005 (Scyllo-Inositol) on Emergence of Neuropsychiatric Symptoms (NPS) in Mild/Moderate Alzheimer's Disease: Results from a 78-Week Phase 2 Study. Neurology 78 (2012).

78 Beyermears, A., Bucci, F. A., Delval, M. \& Cruz, E. DIETARY MYOINOSITOL EFFECT ON SUGAR CATARACTOGENESIS. Pharmacology 39, 59-68, doi:10.1159/000138572 (1989).

79 Ruf, J. C., Ciavatti, M., Gustafsson, T. \& Renaud, S. EFFECT OF D-MYO-INOSITOL ON PLATELET-FUNCTION AND COMPOSITION AND ON CATARACT DEVELOPMENT IN STREPTOZOTOCIN-INDUCED DIABETIC RATS. Biochemical Medicine and Metabolic Biology 48, 46-55, doi:10.1016/0885-4505(92)90047-3 (1992).

80 Jiang, Z. R., Chung, S. K., Zhou, C., Cammarata, P. R. \& Chung, S. S. M. Overexpression of Na+-dependent myoinositol transporter gene in mouse lens led to congenital cataract. Investigative Ophthalmology \& Visual Science 41, 1467-1472 (2000). 
bioRxiv preprint doi: https://doi.org/10.1101/2020.12.16.423154; this version posted January 9, 2022. The copyright holder for this preprint (which was not certified by peer review) is the author/funder, who has granted bioRxiv a license to display the preprint in perpetuity. It is made available under aCC-BY-NC 4.0 International license.

81 Chhetri, D. R. Myo-Inositol and Its Derivatives: Their Emerging Role in the Treatment of Human Diseases. Frontiers in Pharmacology 10, doi:10.3389/fphar.2019.01172 (2019).

82 Bassnett, S. \& Duncan, G. THE INFLUENCE OF PH ON MEMBRANE CONDUCTANCE AND INTERCELLULAR RESISTANCE IN THE RAT LENS. J. Physiol.-London 398, 507-521, doi:10.1113/jphysiol.1988.sp017054 (1988).

83 Quintanar, L. et al. Copper and Zinc lons Specifically Promote Nonamyloid Aggregation of the Highly Stable Human gamma-D Crystallin. ACS Chem Biol 11, 263-272, doi:10.1021/acschembio.5b00919 (2016).

84 Borgia, M. B., Nickson, A. A., Clarke, J. \& Hounslow, M. J. A Mechanistic Model for Amorphous Protein Aggregation of Immunoglobulin-like Domains. J. Am. Chem. Soc. 135, 6456-6464, doi:10.1021/ja308852b (2013).

85 Rygula, A. et al. Raman spectroscopy of proteins: a review. Journal of Raman Spectroscopy 44, 1061-1076 (2013).

86 Lippert, J., Tyminski, D. \& Desmeules, P. Determination of the secondary structure of proteins by laser Raman spectroscopy. Journal of the American Chemical Society 98, 7075-7080 (1976).

87 Sane, S. U., Cramer, S. M. \& Przybycien, T. M. A holistic approach to protein secondary structure characterization using amide I band Raman spectroscopy. Analytical biochemistry 269, 255-272 (1999).

88 Wen, Z. Q. Raman spectroscopy of protein pharmaceuticals. Journal of pharmaceutical sciences 96, 2861-2878 (2007). 